\title{
A chloride efflux transporter OsBIRG1 regulates grain size and salt tolerance in rice
}

Zhijie Ren ${ }^{1}$, Fenglin Bai ${ }^{1}$, Jingwen $\mathrm{Xu}^{1}$, Li Wang ${ }^{1}$, Xiaohan Wang ${ }^{1}$, Qian Zhang ${ }^{1}$, Changxin Feng ${ }^{1}$, Qi Niu ${ }^{1}$, Liying Zhang ${ }^{1}$, Mengou Li $^{2}$, Jiali Song ${ }^{1}$, Fang Bao ${ }^{1}$, Liangyu Liu ${ }^{1}$, Yikun $\mathrm{He}^{1}$, Ligeng Ma ${ }^{1}$, Jinlong Qiu ${ }^{2}$, Wang Tian ${ }^{3,4}$, Congcong $\mathrm{Hou}^{1,4}$, Legong $\mathrm{Li}^{1,4}$

${ }^{1}$ College of Life Sciences, Capital Normal University, and Beijing Key Laboratory of Plant Gene Resources and Biotechnology for Carbon Reduction and Environmental Improvement, Beijing 100048, China

${ }^{2}$ Insitute of Microbiology, Chinese Academy of Sciences, Beijing 100101, China

${ }^{3}$ School of Advanced Agricultural Sciences, Peking University, Beijing 100871, China

\section{${ }^{4}$ Correspondence:}

Legong Li (1gli@cnu.edu.cn), Congcong Hou (ongconghou@ cnu.edu.cn), or Wang Tian(wtian@pku.edu.cn).

Tel: +86-010-68902593

Running title: A chloride efflux transporter controls grain size and salt tolerance 


\section{Summary}

Grain size is determined by the number of cells and cell size of the grain. Regulation of grain size is crucial for improving crop yield. However, the genes and underlying molecular mechanisms controlling grain size remain elusive. Here we report a member of Detoxification efflux carrier (DTX)/Multidrug and Toxic Compound Extrusion (MATE) family transporter, BIG RICE GRAIN 1 (BIRG1), negatively regulates the grain size in rice. BIRG1 is highly expressed in reproductive organs and roots. In birgl grain, the size of the outer parenchyma layer cells of spikelet hulls is noticeably larger but the cell number is not altered compared with that in the wild-type (WT) grain. When expressed in Xenopus oocytes, BIRG1 exhibits chloride efflux activity. In line with the role of BIRG1 in mediating chloride efflux, the birg1 mutant shows reduced tolerance to salt stress under which the chloride level is toxic. Moreover, the birgl grains contain higher level of chloride compared to WT grains when grown under normal paddy field. The birgl roots accumulate more chloride than those of WT under saline condition. Collectively, our findings suggest that BIRG1 functions as a chloride efflux transporter regulating grain size and salt tolerance via controlling chloride homeostasis in rice.

Keywords: Rice, grain size, DTX/MATE, chloride efflux transporter, salt tolerance 


\section{Introduction}

Rice, as one of the most important crops in the world, provides the staple food for about half of the world's population (Li et al., 2018). Thus, investigation of the genetic basis and molecular mechanism for rice grain yield regulation is of great significance. Grain size is an important yield trait, which is determined by grain width, length and thickness (Zuo and Li, 2014). In recent years, many quantitative trait loci (QTLs) and genes regulating grain size have been cloned and studied, providing insights into the molecular basis of the regulation of grain size (Cui et al., 2003; Huang et al., 2013; Ishimaru et al., 2013; Liu et al., 2015; Mao H, 2010; Shomura et al., 2008). However, additional genes that maintains ionic balance and controls this important trait remain to be identified.

Chloride $\left(\mathrm{Cl}^{-}\right)$is traditionally considered as a micronutrient (Broyer et al., 1954). It is involved in the stabilization of the photosystem II (PSII) and the regulation of enzyme activities such as the asparagine synthethase, amylases, and the tonoplast $\mathrm{H}^{+}$-ATPase (Metzler 1979; Rognes 1980; Churchill \& Sze 1984; Kawakami et al., 2009). As a mobile anion in plant, $\mathrm{Cl}^{-}$also plays main roles in the stabilization of the electric potential of cell membranes and the regulation of $\mathrm{pH}$ gradients (White \& Broadley 2001; Hänsch \& Mendel 2009). In addition, $\mathrm{Cl}^{-}$serves as an osmotically active solute in certain tissues or single cells (e.g. guard cells) (Zonia et al., 2002; Hedrich 2012; Munemasa et al., 2015). On the other hand, $\mathrm{Cl}^{-}$can be toxic to plants at high concentrations. The detrimental effects of high $\mathrm{Cl}^{-}$concentration may be executed by interference with cell cycle regulation and inhibition of ribosomal enzymes that catalyze protein synthesis (Geilfus, 2018) . Intriguingly, it has been reported that, during salt stress, the effects of $\mathrm{Cl}^{-}$can be additive and/or synergistic to those of $\mathrm{Na}^{+}$. For instance, treatments with $\mathrm{NaCl}$ can affect the growth and physiology of rice more than treatments that contain only high concentrations of $\mathrm{Cl}^{-}$or $\mathrm{Na}^{+}$ (Khare et al., 2015; Kumar \& Khare 2015). $\mathrm{Cl}^{-}$transport occurs primarily via the symplastic pathway (Brumós et al., 2010). Up to date, several plant transport proteins 
permeable to $\mathrm{Cl}^{-}$have been identified and characterized, which includes AtCLCa (Chloride Channel) (de Angeli et al., 2006), AtCLCc (Jossier et al., 2010), AtCLCg (Nguyen et al., 2016), and AtALMT9 (ALuminium-Activated Malate Transporter) (Kovermann et al., 2007; de Angeli et al., 2013) in the shoot and AtNPF2.4 (Nitrate transporter /Peptide transporter Family) (Li et al., 2016), AtNPF2.5 (Li et al., 2017), AtSLAHs (SLow-type Anion Channel Associated/SLAC1 Homologues) (Cubero et al., 2016; Qiu et al., 2017), AtALMT9 (Baetz et al., 2016), AtCLCc (Jossier et al., 2010), CCCs (Cation $\mathrm{Cl}^{-}$Cotransporter) (Zhang et al., 2010), AtNPF7.2, AtNPF7.3 (Li et al., 2017) and AtALMT12 (Meyer et al., 2010; Sasaki et al., 2010) in the root. Recently, it was reported that two tonoplast DTX/MATE proteins, DTX33 and DTX35, mediate chloride influx into the vacuole, which is essential for cell turgor regulation in Arabidopsis (Zhang et al., 2017).

DTX/ MATE transporters are conserved from bacteria to plants and animals (Brown et al., 1999; Hiroshi et al., 2006; Li et al., 2002). In Arabidopsis, several DTX/MATE members have been reported to function as transporters of organic acids and secondary metabolites (Li et al., 2002; Marinova et al., 2007; Yokosho et al., 2009; Zhang et al., 2014). For example, AtDTX1 mediates the efflux of plant-derived alkaloids, antibiotics, and other toxic compounds (Li et al., 2002). AtTT12 (TRANSPARENT TESTA 12) acts as a vacuolar flavonoid/ $\mathrm{H}^{+}$-antiporter active in proanthocyanidin-accumulating cells of the seed coat (Marinova et al., 2007). The FRD3 (FERRIC REDUCTASE DEFECTIVE 3) mediates efflux of citrate into the root vasculature, which is necessary for efficient iron translocation (Green and L., 2004). The EDS5 (ENHANCED DISEASE SUSCEPTIBILITY 5) possibly functions as an SA (SALICYLIC ACID) transporter involved in the SA-dependent pathogen response pathway (Ding et al., 2014). Our previous work indicates that AtDTX50 may serve as an ABA (ABSCISIC ACID) efflux transporter (Zhang et al., 2014). RHC1 (RESISTANT TO $\mathrm{HIGH} \mathrm{CO}_{2}$ 1) may act as a $\mathrm{HCO}_{3}{ }^{-}$sensing component essential for $\mathrm{CO}_{2}$-induced stomatal closure (Tian et al., 2015). 
The rice genome encodes about 45 members in the DTX/MATE family (Wang et al., 2016). Among them, three members (OsFRDL1 (FRD3-LIKE PROTEIN 1), OsFRDL2 and OsFRDL4) belong to the group of citrate transporters (Yokosho et al., 2009). OsFRDL1 is involved in the efficient translocation of Fe from the roots to the shoots (Yokosho et al., 2009). OsFRDL2 is involved in the Al-induced secretion of citrate (Kengo et al., 2016). OsFRDL4 is responsible for external detoxification of Al (Yokosho et al., 2016). The DTX/MATE family proteins transport a wide range of substrates and functions differently in various physiological processes. In this study, we report an uncharacterized member, BIG $\underline{\text { RICE }}$ GRAIN 1 (BIRG1), functions as a chloride effluxer controlling chloride homeostasis, which negatively regulates grain size and positively contribute to salt tolerance in rice.

\section{Results}

\section{Disruption of BIRG1 increases grain size in rice}

To explore the potential roles of DTX/MATE family genes in rice grain, we first analyzed the expression levels of the DTX/MATE family genes in spikes by searching the Rice Genome Annotation Project database (http://rice.plantbiology.msu.edu/). The results showed that 10 of the $46 D T X / M A T E$ family genes are highly expressed in spikes (Table S1). Next, we individually mutated Os06g29950, Os01g49120, Os02g57570, Os03g64150 and Os08g43250 in the Nipponbare background using either TALENs (Transcription Activator-Like Effectors Nucleases) or CRISPR/Cas9 (Clustered Regularly Interspaced Short Palindromic Repeats-CRISPR-Associated protein 9) technologies (Fig. S1a). We found that a TALENs-mutagenized mutant harboring 7-base deletion at the ORF of Os03g64150, showed increased grain size (Fig. 1a, b). We named it as $\underline{B} I G \underline{R I C E} \underline{G R A I N ~} 1$ (BIRG1). To further test if the increased grain size is caused by the loss-of-function mutation of the BIRG1, we generated an independent BIRG1 knockout line, birg1-2 (harboring 1-base deletion at the target site that causes a frame shift), using CRISPR/Cas9 technology (Fig. 1a). Indeed, compared with the WT, birg 1-1 and birg 1-2 both had significantly increased 
grain length, width and thickness (Fig. 1e, f; Fig. S1f, g, h, i). As a result, the 1,000-grain weight was increased by $13.03 \%$ and $13.44 \%$ in birgl-1 and birg1-2, respectively (Fig. 1d; Fig. S1c, d, e). When plants were grown naturally in three different paddy fields where the $\mathrm{Cl}^{-}$level varied but is not detrimental, the increased grain size phenotype of birg1 mutant was observed consistently (Fig. S2). This result indicates that BIRG1 protein regulates rice grain size under a wide range of external $\mathrm{Cl}^{-}$level. Moreover, we generated BIRGl knockdown mutants using RNA interference (RNAi) technology. Similar to birgl-1 and birg1-2, the BIRG1 RNAi lines, $R i-1$ and $R i-2$ also showed increased grain length and width (Fig. S3). Taken together, these data indicate that BIRG1 is a negative regulator of the grain size in rice.

Compared with the WT, the birg1-1 and birg1-2 mutants showed negligible difference in the gross morphology from the seedling stage to vegetative developmental stage (Fig. S1j, k). However, at mature stage, plant height of birgl mutants was slightly decreased which attributed to reduced length of the uppermost internode (Fig. 1c; Fig. S1I; Fig. S4a, b). The architecture of the birgl mutants was more upright, short and compact (Fig. 1c), which endowed the birgl mutants an increased lodging resistance (Fig. S5). Moreover, the birg1 mutants displayed noticeable chlorosis at the leaf tips and edges (Fig. 1c). Compared with the WT, there was no difference at flag leaf length and width, tiller number and grain density of per panicle in the birgl (Fig. S4c, d, e, h). However, the panicle length of the birgl was shorter than that of the WT (Fig. S4f). Grain number per panicle and seed setting rate of birgl were reduced compared to those of the WT (Fig. S4g, i). These results suggest that BIRG1 may influence the balance between grain number and grain size. The birgl mutant displayed pleotropic phenotypes as described. We postulated that some of the phenotypes, such as decreased plant height, reduced grain number and lower seed setting rate, may attribute to compromised photosynthetic capacity of the birgl mutant. To test this possibility, we measured the photosynthetic rate of birg1 
and WT. Our results showed that, indeed, the photosynthetic rate of birgl is significantly lower than that of the WT (Fig.S6).

Expression level of BIRG1 is induced in reproductive organs and its protein localizes at the plasma membrane

We next performed reverse transcription quantitative PCR (RT-qPCR) to investigate the spatial expression profile of $B I R G 1$. The RT-qPCR results revealed that BIRG1 was expressed in the root, culm, leaf, sheath, anther, and panicle, with the relatively higher expression levels in the root and anther (Fig. S7a). Importantly, during the earlier stage of panicle development, the expression level of BIRGl increased significantly with panicle elongation (Fig. 2a). In addition, we cloned a 3.2-kb promoter region of BIRG1 and generated the promoter-GUS transgenic rice plants. GUS staining showed that BIRGI was expressed abundantly in the root, culm node, grain, leaf and guard cells (Fig. 2b), which is consistent with the results from RT-qPCR analysis. In the panicles, strong GUS staining was also observed in spikelet hulls, pistil, anther, pollens and seeds (Fig. 2c). The expression level is induced in reproductive organs, not in other tissues, indicating BIRG1 might be involved in the grain filling.

Previous study has shown that several members of DTX/MATE family protein, for examples DTX35 and DTX33, are localized to tonoplast (Zhang et al., 2017). As the subcellular localization of a transporter is critical for its function, we first examined the subcellular localization of BIRG1 by the GFP fusion approach. We made BIRG1::GFP fusion constructs under the control of $35 S$ promoter and transiently expressed them in rice protoplasts and tobacco (Nicotiana benthamiana) epidermal cells, respectively. In rice protoplast, the green fluorescence of BIRG1-GFP was observed at the protoplast plasma membrane compared with the diffuse cytoplasmic localization of the eGFP control (Fig. 2d). Consistently, in tobacco epidermal cells, the BIRG1-GFP was targeted at the plasma membrane, whereas the eGFP control was distributed in the nucleus and plasma membrane (Fig. 2e). These results indicated that BIRG1 is localized to the plasma membrane. 


\section{The birg1 mutant shows accelerated grain filling rate}

Given the importance of grain filling in contributing to the seed size, we investigated the grain filling rate by measuring fresh and dry weight of the grains and brown rice during grain filling (Fig. 3a). All fresh and dry weight of grains and brown rice of birg 1-1 were higher than those of the WT starting from $\sim 12$ days after fertilization (DAF). The differences became more significant along with the grain development. The maximum grain filling rate was achieved at $\sim 21$ DAFs. At this point, fresh and dry weight of the grains of birg $1-1$ were $18.1 \%$ and $21.1 \%$ higher than the WT; Fresh and dry weight of the brown rice of birgl-1 were $16.0 \%$ and $18.2 \%$ higher than the WT, respectively (Fig. 3b, $\mathbf{c}, \mathbf{d}, \mathbf{e}$ ). These data indicates that the grain filling rate of birgl is accelerated compared to the WT. As the grain filling is actually a process of starch accumulation, we examined the expression levels of five genes related to starch synthesis RSR1/AP2/EREBP (RICE STARCH REGULATOR 1/AP2/EREBP FAMILY TRANSCRIPTION FACTOR), AGPL2 (ADP-GLUCOSE PYROPHOSPHORYLASE LARGE SUBUNIT 2), GBSSI (GRANULE-BOUND STARCH SYNTHASE 1), GLUCAN (GLUCAN SYNTHASE), BEI (BRANCHING ENZYME I) (Wang et al., 2015). Our result showed that all these five genes were up-regulated to different extent in the birgl mutants, which is correlated with the faster grain filling rate of birgl (Fig. S7b).

On the basis of the observations that the filling rate of the birgl mutant is accelerated and the birgl matures earlier than the WT (Fig. 3a), we asked whether the starch accumulation in the endosperm of the birgl mutant is affected. We found that the mutant had a loose endosperm texture and loose, small starch granules, whereas the WT starch accumulated relatively densely (Fig. S8a), indicating that the grouting of the mutant stopped before it was fully completed. In addition, there was no significant difference in crude protein content and moisture content between the grains of WT and birgl (Fig. S8b, c). The amylose content in the birgl grain was significantly higher than that in the WT (Fig. S8d). At the same time, the viscosity of 
birgl pasting starch is higher than that of the WT (Fig. S8e), which may make the birgl rice taste better.

\section{Cytological alterations in birg1 mutant grain}

The birgl mutants showed increased grain size. It has been proposed that grain size is determined by the size of spikelet hull, which consists of a lemma and a palea ( $\mathrm{Na}$ and $\mathrm{Li}, 2015)$. Changes in both cell size and cell number affect the final size of a spikelet hull ( $\mathrm{Na}$ and $\mathrm{Li}, 2015)$. To uncover the cellular mechanism for BIRG1 in grain size, we investigated cells in WT and birgl spikelet hulls using a scanning electron microscope. We found that, in birg1-1 and birg1-2, the lemma cell length and width were greater than those in the WT (Fig. 4a, b). The palea cell length in birg1-1 and birg 1-2 mutants were greater than that in the WT (Fig. 4a, c), but there was no significant difference in cell width of the palea between the mutants and the WT (Fig. $4 c)$.

Next, histological analysis was performed on the spike hulls two days before pollination (Fig. 4d, e). The results showed that the outer parenchymal cells of the birg 1-1 and birg 1-2 mutants were larger than those of the WT (Fig. 4f, i), thereby increasing the total length of the outer parenchymal cells (Fig. 4f, 4g). Further statistical analysis on the number of outer parenchyma cells found no significant difference between WT and mutants (Fig. 4h). In support of these results, expression levels of five cell cycle-related genes CDKA1 (CYCLIN-DEPENDENT KINASE A-1), CYCD1;1 (CYCLIN -D1-1), CYCT1 (CYCLIN -T1), H1 (CYCLIN -H1) and E2F2 (E2F TRANSCRIPTION FACTOR) in the WT and birgl were comparable, whereas, among the five cell expansion-related genes tested (EXA5, EXA10, EXB3, EXPB4 and $E X B 7), E X B 3$ and EXB7 were significantly elevated in young panicles of the birg1 mutant (Fig. S4c, d) (Li et al., 2011; Liu et al., 2015). Together, these results demonstrated that the larger spikelet in birgl was caused by the enlargement of the single cell but not the change in cell number, suggesting that BIRG1 regulates spikelet size by affecting cell expansion. 


\section{BIRG1 can mediate chloride efflux}

The genetic evidences above demonstrated that loss-of-function of BRIG1 resulted in expanded cell size and increased grain size. As we know, BIRG1 is a member of the MATE family proteins that are found in bacteria, fungi, plants, and animals (Brown et al., 1999; Hiroshi et al., 2006; Li et al., 2002). Studies have shown that MATE proteins transport various substrates. Among the plant MATE-type transporters, some PM-focused members select citric acids as substrates and some tonoplast localized members function as anion channels that mediate transport of halogen ion (Magalhaes et al., 2007; Maron et al., 2009; Zhang et al., 2017).

To investigate the electrophysiological properties of BIRG1, we expressed the BIRG1 protein in the Xenopus laevis oocytes and examined its activity using various ionic buffers. Two-electrode voltage clamp (TEVC) recording showed that the oocytes injected with BIRG1 cRNA produced large inward currents of $~ 2200 \mathrm{nA}$, at $-140 \mathrm{mV}$ in bath solution containing $48 \mathrm{mM} \mathrm{NaCl}$, which were not observed in the control cells (water injected) (Fig. 5a). By convention, inward currents reflect positive charge influx or negative charge efflux. When we replaced $\mathrm{Cl}^{-}$in the bath solution with gluconate (an impermeable anion), the large inward currents disappeared in BIRG1-expressing cells. These results indicate that the inward currents may be produced by chloride efflux (Fig. 5a, b). Upon changing the bath $\mathrm{Cl}^{-}$concentration, the magnitude of the inward current changed proportionally (Fig. 5c, d), indicating that the BIRG1-mediated inward currents were dependent on external $\mathrm{Cl}^{-}$. In addition, we applied a typical anion channel blocker 4,4'-diisothiocyanostilbene-2,2'-disulfonic acid (DIDS) to the bath solution and observed inhibition of the BIRG1 currents (Fig. 5e, f). We also examined the anion selectivity of BIRG1 by perfusing the bath solution with various anions. The results showed a selectivity sequence of $\mathrm{Br}^{-}>\mathrm{Cl}^{-}>$ $\mathrm{NO}_{3}{ }^{-} \approx \mathrm{SO}_{4}{ }^{2-}>$ malate ${ }^{2-}>$ gluconate $($ Fig. 5a, b). Next, to further clarify the rectification property of BIRG1, we removed extracellular $\mathrm{Cl}^{-}$by using a gluconate-based bath medium and utilized the $\mathrm{Cl}^{-}$releasing from the electrodes as the charge carrier. The method was used successfully for recording the channel activity of 
SKOR, an outward potassium channel from Arabidopsis (Gaymard et al., 1998; Li et al., 2008a). Intriguingly, we found that, similar to what observed in SKOR-expressing oocytes, the BIRG1-expressing oocytes only produced small inward currents at the time point of 1 minute (Fig. $\mathbf{5 g}, \mathbf{h}, \mathbf{i}, \mathbf{j}$ ). However, as time goes by, the inward currents became remarkably larger in the same oocyte, suggesting increased $\mathrm{Cl}^{-}$efflux across the plasma membrane (Fig. 5g, h, i, j). No inward current was observed in water-injected control oocytes (Fig. $\mathbf{5 g}, \mathbf{h}, \mathbf{i}, \mathbf{j}$ ). Taken together, these data confirmed that BIRG1 can mediate anion efflux, especially inorganic anions, such as $\mathrm{Cl}^{-}$.

\section{BIRG1 contributes to salt tolerance in rice}

Under high salinity, $\mathrm{Cl}^{-}$usually accumulates to toxic level in the cytoplasm. Our results demonstrated that BIRG1 is expressed highly in the roots and it exhibits chloride efflux activity in oocytes. We speculated that BIRG1 may expel chloride from the cytosol to the apoplast to reduce the overall chloride content in the plant thus playing a role in salt tolerance. To test this possibility, the WT and birgl seeds were geminated and grown in half strength MS medium containing $100 \mathrm{mM}$ or $150 \mathrm{mM}$ $\mathrm{NaCl}$ for 14 days. Clearly, the growth of WT plants was severely inhibited by the presence of $100 \mathrm{mM}$ or $150 \mathrm{mM} \mathrm{NaCl}$ (Fig. 6a). Intriguingly, the inhibition effect of $\mathrm{NaCl}$ on birgl mutants was more pronounce, as indicated by the observation that the roots and shoots of birgl mutants are shorter than those of WT under the salt stress conditions (Fig. $\mathbf{6 b}, \mathbf{c}, \mathbf{d}, \mathbf{e}, \mathbf{f}, \mathbf{g}$ ). It is well known that high salinity imposes both ionic and osmotic stresses to plants. To distinguish if the hypersensitivity of birgl to $\mathrm{NaCl}$ is caused by its osmotic effect, the WT and birgl seeds were also subjected to 300 $\mathrm{mM}$ mannitol for 14 days. Our results showed that the growth of WT and birgl mutants were greatly suppressed to similar degree (Fig. 6h, i), indicating that BIRG1 is not involved in hyper-osmolality stress. Moreover, we found that when grown in the medium containing $150 \mathrm{mM} \mathrm{NaNO}_{3}$, the WT and birgl showed no morphological difference (Fig. 6h, i), suggesting that BIRG1 does not respond to $\mathrm{NO}_{3}{ }^{-}$, which is in line with the result from TEVC experiment that BIRG1 exhibits very low 
permeability to $\mathrm{NO}_{3}^{-}$(Fig. 5a, b). Together, these results demonstrated that BIRG1-mediated chloride efflux contributes to salt tolerance in rice.

\section{BIRG1 regulates chloride homeostasis in rice}

$\mathrm{Cl}^{-}$is one of the essential elements supposedly needed only in small quantities for healthy growth of plants (about 50-100 $\mu \mathrm{M}$ in the nutrient media). Under high external $\mathrm{Cl}^{-}$condition, plant cells accumulate excessive $\mathrm{Cl}^{-}$which causes toxicity. Thus, the chloride homeostasis in plant should be finely regulated. To further test if BIRG1-mediated chloride efflux affects chloride homeostasis in plant, we measured the chloride contents in WT and birgl mutant. As shown in Fig. 7, the $\mathrm{Cl}^{-}$content in the birgl mutant grains was obviously higher than that in the WT grains when grown under normal paddy field (Fig. 7a), suggesting that BIRG1 regulates chloride homeostasis in the grain and the chloride content in the grain is positively correlated to the grain size. Furthermore, the $\mathrm{Cl}^{-}$contents in the plants grown on $1 / 2 \mathrm{MS}$ medium and 1/2MS supplemented with $100 \mathrm{mM} \mathrm{NaCl}$ for 14 days were also determined. When grown on $1 / 2 \mathrm{MS}$, the $\mathrm{Cl}^{-}$content in the roots of WT and birgl mutant was comparable. The same is true in shoots (Fig. 7b, c). When grown on $1 / 2 \mathrm{MS}$ supplemented with $100 \mathrm{mM} \mathrm{NaCl}$, WT root and shoot accumulated more $\mathrm{Cl}^{-}$ compared with those grown on 1/2MS (Fig. 7b, c, d, e). In birgl mutant, the $\mathrm{Cl}^{-}$ content in shoot was comparable to that in WT (Fig. 7e). However, the birgl roots contain significantly more $\mathrm{Cl}^{-}$than WT roots (Fig. 7d). These results indicated that, in addition to its role in controlling chloride homeostasis in grain under normal growth condition, BIRG1 is essential for the chloride homeostasis in root under high salinity condition.

\section{Discussion}

In this study, we demonstrate that a member of DTX/MATE family transporters, BIRG1, negatively regulates grain size by specific controlling cell size but not cell number of the spikelet hull. BIRG1 localizes to the PM and mainly expressed in reproductive organs and roots. BIRG1 shows $\mathrm{Cl}^{-}$efflux activity in oocyte. In line with 
the transport activity of BIRG1, the birgl mutant is less tolerant to high external $\mathrm{Cl}^{-}$. The birgl grains contain higher level of chloride compared to WT grains when grown under normal paddy field and the birgl roots accumulate more chloride than those of WT under high salinity. Thus, we conclude that BIRG1 functions as a $\mathrm{Cl}^{-}$effluxer that regulates grain size and salt tolerance by controlling chloride homeostasis in rice.

Grain size is one of the key agronomic traits that determine grain yield, but the genetic and molecular mechanisms of grain size control in rice are still unclear. Our finding that BIRG1 negatively regulates grain size and the birgl mutant grain contains more $\mathrm{Cl}^{-}$than that of WT indicates that $\mathrm{Cl}^{-}$content is positively correlated to the grain size under normal growth condition. It was demonstrated that the larger spikelet in birgl mutant resulted from the enlargement of the outer parenchyma cells (Fig. 4f, i). Meanwhile, some of the cell expansion-related genes were significantly elevated in young panicles of the birgl mutant (Fig. S7c, d). Previous studies reported that $\mathrm{Cl}^{-}$stimulates the activity of the tonoplast-type $\mathrm{H}^{+}$-translocating ATPase (Churchill and Sze, 1984; Randall and Sze, 1986), which contributes to the intrusion of anions (e.g. nitrate and chloride) into the vacuole. The anions, together with their counterparts, serve as osmotica in the vacuole, driving the water flow and enhancing cell turgor pressure. In this way, $\mathrm{Cl}^{-}$is thought to promote turgor-driven cell expansion (Chen et al., 2016; Franco-Navarro et al., 2016; L.B. Smart et al., 1998). This may explain why the outer parenchyma cells of birgl mutant grain are enlarged. At the meantime, turgor pressure may serve as a signal that activates the expression of cell expansion-related genes to facilitate cell expansion (Beauzamy et al., 2014; Fricke et al., 2000).

We also noticed that under normal growth condition, the yield of birgl mutant is slightly lower than that of WT (Fig S4m), indicating a complicated physiological effect of $\mathrm{Cl}^{-}$homeostasis in regulating agronomic traits of rice. Nevertheless, it will be worthwhile to figure out how BIRG1 is connected to the molecular pathway of grain size and yield regulation in the future. 
$\mathrm{NaCl}$ is generally the dominant salt in saline soils. Both $\mathrm{Na}^{+}$and $\mathrm{Cl}^{-}$cause detrimental effect on plant growth and development if accumulated at high concentrations in the cytoplasm. However, most previous researches on salt tolerance have been focusing on $\mathrm{Na}^{+}$. Thus, it is still elusive that how $\mathrm{Cl}^{-}$is transported and how $\mathrm{Cl}^{-}$homeostasis is regulated under salt stress (Teakle and Tyerman, 2010). Our finding that BIRG1 mediates $\mathrm{Cl}^{-}$exclusion in the root thereby contributing to the salt tolerance advances our understanding of $\mathrm{Cl}^{-}$transport mechanisms under salt stress. More importantly, it is suggested that BIRG1 may server as a molecular target for engineering rice with improved salt tolerance.

Organic compounds, including a number of therapeutic drugs, have been shown to be substrates of DTX/MATE transporters in bacteria and animals (Shiomi et al., 1995; Morita, 1998). The DTX /MATE proteins in plants constitute a superfamily, and some of them have been shown to transport organic acids or secondary metabolites (Li et al., 2002; Magalhaes et al., 2007; Maron et al., 2009; Yokosho et al., 2009; Zhang et al., 2014; Kengo et al., 2016). For example, MATE proteins play a role in aluminum tolerance by mediating citric acid efflux from root cells to chelate $\mathrm{Al}^{3+}$ (Yokosho et al., 2011). Recently, two tonoplast MATE/DTX proteins, DTX33 and DTX35, have been demonstrated to function as turgor-regulating chloride channels in Arabidopsis (Zhang et al., 2017), expanding the diversity of substrates for plant DTX /MATE. Our finding that rice BIRG1 possess a strong $\mathrm{Cl}^{-}$efflux activity that provides the first example in monocots and further solidifies the notion that some plant MATE/DTX proteins are halogen ion/anion channels, which breaks the dogma that DTX/MATE proteins are transporters of organic compounds.

\section{Methods}

\section{Plant Materials and Growth Conditions}

The japonica Nipponbare, as WT for analyses, was kindly provided by prof. Lu Tiegang. The rice plants were grown in paddy fields located in different regions of China, under natural conditions or on 1/2 MS (Murashige and Skoog) $+1 \%$ Sucose + 
$0.6 \%$ Agar $(\mathrm{pH} 5.8)$ in a growth chamber $\left(26-28^{\circ} \mathrm{C}, 16-\mathrm{h}\right.$ light/8-h dark). The mutants containing birg1-1, birg1-2, RNAi lines and other $d t x s$ were achieved by using either TALENs or CRISPR/Cas9 technologies in the Nipponbare background. TALENs-birg 1-1 was designed and operated by prof. Gao Caixia'Lab. CRISPR/Cas9 lines were achieved from Beijing Genovo company.

\section{RNA extraction and Real-Time qRT-PCR Analysis}

Total RNA was isolated from the various organs of birgl and wild-type plants using Trizol reagent (Life Technologies). About $1 \mu \mathrm{g}$ RNA was reversely transcribed using oligo (dT) primer and was reverse-transcribed with Superscript III following the manufacturer's instructions (Life Technologies). Quantitative PCR experiments were performed using SYBR Green PCR Master Mix (Takara, Otsu, Japan) with Bio-Rad CFX96 real-time PCR machine. The primers are listed in Supporting Information table 2. The rice ACTIN1 gene was used as internal control. Values are means $\pm \mathrm{SD}$ of three biological repeats. Changes in transcription were calculated using the 2 (-Delta Delta C (T)) method (Livak and Schmittgen, 2001). The primers are described in Supporting Information table 2.

\section{Vector Construction and Plant Transformation}

For the subcellular localization assay, complementary cDNAs of BIRG1 was inserted into $p \mathrm{E} 3242-\mathrm{GFP}$ to produce the $35 \mathrm{~S}::$ BIRG1-GFP constructs. Upon sequence confirmation, BIRG1 full-length coding sequences were cloned into $p$ CAMBIA1302 to generate the $p$ CAMBIA1302-35S: BIRG1 for tobacco epidermal leaf cells transiently transformation (Waadt and Kudla, 2008; Waadt et al., 2008). For the GUS-staining assay, a 3.2-kb native promoter was cloned into $p$ CAMBIA1300-GN vector to generate $p$ CAMBIA1300GN-PRO BIRG1::GUS construct. To generate BIRG1-RNAi construct, a 300-bp gene-specific fragment of BIRG1 coding sequence was amplified and cloned into pTCK309 vector. All recombinant constructs were transformed into the rice genome by agrobacterium tumefaciens mediated 
transformation methods as described previously (Komari, 2010). The primer sequences for vector construction are listed in Supporting Information table 2.

\section{GUS staining and scanning electronic microscopy observation}

GUS staining activity was detected according to the method as previously described (Jefferson and R., 1989). The samples were treated in GUS staining buffer overnight at $37^{\circ} \mathrm{C}$. The samples were then cleared in $70 \%-80 \%-90 \%-100 \%$ ethanol to remove chlorophy 11 . The observed staining patterns were recorded with microscope (leica and Zeiss Stemi SV11). The spikelet hulls and dried seeds were prepared for scanning electron microscopy (HITACHI, S-3000N) observation following previous description (Jin et al., 2011).

\section{Measurement of grain filling rate}

Representative samples of 200 grains from the main panicle at 2, 3, 6, 9, 12, 15, 18 , 21, 24, 27 and $30 \mathrm{~d}$ after fertilization (DAF) were harvested. Half of them were used to measure grain fresh and dry weight. And the other half were carefully dehusked by hand and used to measure brown rice fresh and dry weight. Every 20 grains or brown rice as one point sample and then calculate its average.

\section{Histological analysis}

Young spikelet hulls were fixed in FAA (5\% glacial acetic acid: 5\% formaldehyde: 50\% ethanol=1:1:18) for $48 \mathrm{~h}$, and then dehydrated in a graded ethanol series $(70 \%, 80 \%$, 90\%, 100\%, and 100\%). Fixed tissues were embedded in Paraplast Plus chips (Sigma) and were cut into $10 \mu \mathrm{m}$ thick sections using a microtome, then gradually rehydrated and dried before toluidine blue staining for light microscopy.

\section{Subcellular localization}

The expression constructs $35 \mathrm{~S}::$ BIRG1-GFP and 35S::GFP were transformed into rice protoplasts by PEG-mediated transfection. And transfection of rice protoplasts were performed according to the method described previously with minor 
modifications (Chen et al., 2006; Yoo et al., 2007; Zhang et al., 2011). The pCAMBIA1302-35S:: BIRG1 construct was transformated into tobacco epidermal leaf cells by agrobacterium-mediated transient expression in $N$. benthamiana as described previously (Olivier et al., 2003; Waadt and Kudla, 2008; Waadt et al., 2008). Confocal images were captured using Zeiss Live 780 equipment. GFP fluorescence was excited at $488 \mathrm{~nm}$ wavelength, and the emission filters were 500-530 nm.

\section{Two-Electrode Voltage-Clamp (TEVC) recording from Xenopus oocytes}

The BIRG1 cDNA was cloned into the pGEMHE oocyte expression vector. The capped cRNA was synthesised with the Ambion mMESSAGE mMACHINE T7 Kit. Each oocytes were injected with $32 \mathrm{nl}$ of the cRNA in $500 \mathrm{ng} \mu \mathrm{l}^{-1}$ or with $32 \mathrm{~nL}$ of RNase-free water (control oocytes) for voltage-clamp recordings. After 3 days incubation in ND96 solution ( $96 \mathrm{mM} \mathrm{NaCl}, 2 \mathrm{mM} \mathrm{KCl}, 1 \mathrm{mM} \mathrm{MgCl} 2,1.8 \mathrm{mM} \mathrm{CaCl}_{2}$, $10 \mathrm{mM}$ HEPES/NaOH, pH7.4) supplemented with $25 \mathrm{~g} \mathrm{~L}^{-1}$ gentamycin at $16-18^{\circ} \mathrm{C}$, oocytes were voltage-clamped using a TEV 200A amplifier (Dagan Corporation) and monitored by computer through Digidata 1440A/D converter and pCLAMP10.4 software (Axon Instruments) as described previously (Liu and Luan, 2001; Tian et al., 2015) with some modifications. All electrodes were filled with $3 \mathrm{M} \mathrm{KCl}$. The bath solutions contained a background of $2 \mathrm{mM} \mathrm{K}$-gluconate, $1 \mathrm{mM} \mathrm{Mg-gluconate}{ }_{2}, 1.8$ $\mathrm{mM} \mathrm{Ca-gluconate}{ }_{2}$ and $10 \mathrm{mM}$ MES/Tris (pH5.6). The bath solutions added with 48 $\mathrm{mM} \mathrm{Cl}-\mathrm{NO}_{3}^{-}, \mathrm{SO}_{4}{ }^{2-}$, Malate $^{2-}, \mathrm{Glu}^{-}$and $\mathrm{Br}^{-}$were used for ion-selective analysis. Different concentrations of Na-Glu $(24,48,96 \mathrm{mM})$ were added to the bath solution for concentration dependence experiments. Perfusion bath solutions contain $48 \mathrm{mM}$ $\mathrm{Cl}^{-}$along with 0,10 or $100 \mathrm{mM}$ DIDS were used for pharmacological analysis.

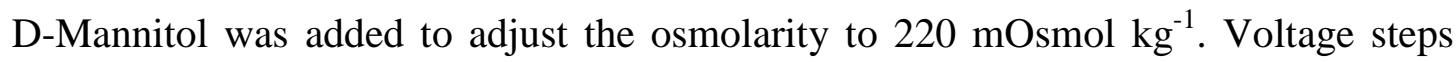
were applied from +40 to $-140 \mathrm{mV}$ in $-10 \mathrm{mV}$ decrements during $2.0 \mathrm{~s}$. And the holding potential was seted to $0 \mathrm{mV}$.

\section{Determination of Rice Grain Quality}


The protein content was measured by the dumas principle method (Kjeltec System 1002, Tecator). The contents of amylose were measured by Double Wavelength colorimetry (Song et al., 2007). Determination gelatinization poperites in cereal and starch by viscograph. All assays were measured in State Administration of Grain.

\section{$\mathrm{Cl}^{-}$Content Measurement}

Every grain sample contains $20 \mathrm{~g}$ muture grain of WT and birgl mutant. Seedlings were grown on $1 / 2 \mathrm{MS}$ or $1 / 2 \mathrm{MS}+100 \mathrm{mM} \mathrm{NaCl}$ for 14 days. Six seedling roots or shoots formed one sample. Before the whole plants were harvested and used for measuring $\mathrm{Cl}^{-}$contents, they should be rinsed at least three times with distilled water. Grain, seedling root or shoot samples were dried at $80^{\circ} \mathrm{C}$ for 2 days. And then grinded to powder. $\mathrm{Cl}^{-}$contents were determined by Ion Chromatography (Thermo ICS-600). Three independent experiments were carried out. The soil $\mathrm{Cl}^{-}$contents were determined by a modified silver titration method that has been described previously (Li et al., 2008b).

\section{The photosynthetic capacity measurement}

The photosynthetic capacity recordings from mature flag leaves of 2-month-old plants were conducted using a Li-6400 infrared (IRGA)-based gas-exchange analyzer with a fluorometer chamber (Li-Cor Inc.) (Li et al., 2016).

\section{Author Contributions}

L.L., C.H., W.T., Z.R. conceived and designed the project. Z.R. and C.H. performed molecular cloning and transgenic plant generation; Z.R. conducted the electrophysiological experiments; C.H., F.B. and C.F. conducted subcellular localization in protoplasts; J.X., L.W., X.W. and Z.R. conducted Promoter-GUS experiments and field experiments; M.L., J.X. and J.Q. conducted TALEN experiments; Q.Z., J.S., Q.N performed RNA extraction, cDNA synthesis, and 
qRT-PCR analysis; All experiments were independently reproduced in the laboratory. Z.R., W.T. and L.L. analyzed the data and wrote the manuscript. All authors discussed the results and commented on the manuscript.

\section{Acknowledgments}

This work was supported by grants from the National Key Research and Development Program of China (YFD0300102-3 to L.G.L.), the General Program of National Natural Science Foundation of China (No. 31872170 to L.L. and No. 31900234 to C. H.), the Key Program of the National Natural Science Foundation of China (31930010 to L. L) and the Capacity Building for Sci-Tech Innovation-Fundamental Scientific Research Funds (19530050165 to L. L.).

\section{Reference}

Baetz, U., Eisenach, C., Tohge, T., Martinoia, E., de Angeli, A. 2016. Vacuolar Chloride Fluxes Impact Ion Content and Distribution during Early Salinity Stress. Plant Physiol 172, 1167-1181.

Beauzamy, L., Nakayama, N., and Boudaoud, A. 2014. Flowers under pressure: ins and outs of turgor regulation in development. Ann Bot 114:1517-1533.

Brown, M.H., Paulsen, I.T., and Skurray, R.A. 1999. The multidrug efflux protein NorM is a prototype of a new family of transporters. Molecular Microbiology 31:(1):394-395.

Broyer, T.C., Carlton, A.B., Johnson, C.M., Stout, P.R. 1954. Chlorine-A micronutrient element for higher plants. Plant Physiol 29, 526-532

Brum ó s, J., Tal Ó N, M., Bouhlal, R.Y.M., Colmenero-Flores, J.M. 2010. $\mathrm{Cl}^{-}$ homeostasis in includer and excluder citrus rootstocks: Transport mechanisms and identification of candidate genes. Plant Cell Environ 33, 2012-2027. 
Chen, S., Tao, L., Zeng, L., Vega-Sanchez, M.E., Umemura, K., and Wang, G.L. 2006. A highly efficient transient protoplast system for analyzing defence gene expression and protein-protein interactions in rice. Molecular Plant Pathology 7:417-427.

Chen, Z.C., Yamaji, N., Fujii-Kashino, M., and Ma, J.F. 2016. A Cation-Chloride Cotransporter Gene Is Required for Cell Elongation and Osmoregulation in Rice. Plant Physiol 171:494-507.

Churchill, K.A., and Sze, H. 1984. Anion-Sensitive, $\mathrm{H}^{+}$-Pumping ATPase of Oat Roots: Direct Effects of $\mathrm{Cl}^{-}, \mathrm{NO}_{3}{ }^{-}$, and a Disulfonic Stilbene. Plant Physi. 76: 490-497.

Cubero-Font, P., Maierhofer, T., Jaslan, J., Rosales, M.A., Espartero, J., D í az-Rueda, P., Müller, H.M., Hürter, A.L., Al-Rasheid, K.A.S., Marten, I., et al. 2016. Silent S-Type Anion Channel Subunit SLAH1 Gates SLAH3 Open for Chloride Root-to-Shoot Translocation. Curr. Biol 26, 2213-2220.

Cui, K., Peng, S., Xing, Y., Yu, S., Xu, C., and Zhang, Q. 2003. Molecular dissection of the genetic relationships of source, sink and transport tissue with yield traits in rice. Theor Appl Genet 106(4):649-58.

De Angeli, A., Zhang, J., Meyer, S., Martinoia, E. 2013. AtALMT9 is a malate-activated vacuolar chloride channel required for stomatal opening in Arabidopsis. Nat. Commun 4, 1804.

Ding, Y., Shaholli, D., and Mou, Z. 2014. A large-scale genetic screen for mutants with altered salicylic acid accumulation in Arabidopsis. Front Plant Sci 5:763.

Franco-Navarro, J.D., Brumos, J., Rosales, M.A., Cubero-Font, P., Talon, M., Colmenero-Flores, J.M. 2016. Chloride regulates leaf cell size and water relations in tobacco plants. J. Exp. Bot 67, 873-891.

Fricke, W., Jarvis, M.C., and Brett, B.C. 2000. Turgor pressure, membrane tension and the control of exocytosis in higher plants. Plant Cell \& Environment 23:999-1003.

Gaymard, Guillaume Pilot, Benoı ^t Lacombe, D.B., Dominique Bruneau, J.B., Nicole Michaux-Ferrie`re, J.-B.T., and Sentenac, H. 1998. Identification and 
Disruption of a Plant Shaker-like Outward Channel Involved in $\mathrm{K}^{+}$Release into the Xylem Sap. Cell 94: 647-655.

Geilfus, C.M. 2018. Review on the significance of chlorine for crop yield and quality. Plant Sci 270:114-122.

Green, and L., S. 2004. FRD3 Controls Iron Localization in Arabidopsis. Plant Physiology 136:2523-2531.

Hänsch, R., Mendel, R.R. 2009. Physiological functions of mineral micronutrients (Cu, Zn, Mn, Fe, Ni, Mo, B, Cl). Curr. Opin. Plant Biol 12, 259-266.

Hedrich, R. 2012. Ion channels in plants. Physiol. Rev 92, 1777-1811.

Hiroshi, Omote, and, Miki, Hiasa, and, Takuya, Matsumoto, and, and Masato. 2006. The MATE proteins as fundamental transporters of metabolic and xenobiotic organic cations. Trends in Pharmacological Sciences 27(11):587-593.

Huang, R., Jiang, L., Zheng, J., Wang, T., Wang, H., Huang, Y., and Hong, Z. 2013. Genetic bases of rice grain shape: so many genes, so little known. Trends Plant Sci 18:218-226.

Ishimaru, K., Hirotsu, N., Madoka, Y., Murakami, N., Hara, N., Onodera, H., Kashiwagi, T., Ujiie, K., Shimizu, B., Onishi, A., et al. 2013. Loss of function of the IAA-glucose hydrolase gene TGW6 enhances rice grain weight and increases yield. Nat Genet 45:707-711.

Jefferson, and R., A. 1989. The GUS reporter gene system. Nature 342:837-838.

Jin, Y., Luo, Q., Tong, H., Wang, A., Cheng, Z., Tang, J., Li, D., Zhao, X., Li, X., and Wan, J. 2011. An AT-Hook gene is required for palea formation and floral organ number control in rice. Developmental Biology 359:277-288.

Jossier, M., Kroniewicz, L., Dalmas, F., le Thiec, D., Ephritikhine, G., Thomine, S., Barbier-Brygoo, H., Vavasseur, A., Filleur, S., Leonhardt, N. 2010. The Arabidopsis vacuolar anion transporter, AtCLCc, is involved in the regulation of stomatal movements and contributes to salt tolerance. Plant J 64, 563-576.

Kawakami, K., Umena, Y., Kamiya, N., Shen, J.R. 2009. Location of chloride and its possible functions in oxygen-evolving photosystem II revealed by X-ray crystallography. Proc. Natl. Acad. Sci. USA 106, 8567-8572. 
Kengo, Y., Naoki, Y., Miho, F.-K., and Ma, J.F. 2016. Functional Analysis of a MATE Gene OsFRDL2 Revealed its Involvement in Al-Induced Secretion of Citrate, but a Lower Contribution to Al Tolerance in Rice. Plant \& Cell Physiology 57(5):976-985.

Khare, T., Kumar V, Kishor PB. 2015. $\mathrm{Na}^{+}$and $\mathrm{Cl}^{-}$ions show additive effects under $\mathrm{NaCl}$ stress on induction of oxidative stress and the responsive antioxidative defense in rice. Protoplasma 252, 1149-1165.

Komari, T. 2010. Efficient transformation of rice (Oryza sativa L.) mediated by Agrobacterium and sequence analysis of the boundaries of the T-DNA. Plant Journal for Cell \& Molecular Biology 6:271-282.

Kovermann, P., Meyer, S., Hoertensteiner, S., Picco, C., Scholz-Starke, J., Ravera, S., Lee, Y., Martinoia, E. 2007. The Arabidopsis vacuolar malate channel is a member of the ALMT family. Plant J 52, 1169-1180.

Kumar, V. and Khare, T. 2015. Individual and additive effects of $\mathrm{Na}^{+}$and $\mathrm{Cl}^{-}$ions on rice under salinity stress. Arch. Agronomy Soil Sci 61, 381-395.

L.B. Smart, F Vojdani, M. Maeshima, and Wilkins, T.A. 1998. Genes involved in osmoregulation during turgor-driven cell expansion of developing cotton fibers are differentially regulated. Plant Physiol. 116:1539-1549.

Li, B., Byrt, C., Qiu, J., Baumann, U., Hrmova, M., Evrard, A., Johnson, A.A.T., Birnbaum, K.D., Mayo, G.M., Jha, D., et al. 2016. Identification of a Stelar-Localized Transport Protein That Facilitates Root-to-Shoot Transfer of Chloride in Arabidopsis. Plant Physiol 170, 1014-1029.

Li, B., Tester, M., Gilliham, M. 2017. Chloride on the move. Trends Plant Sci 22, $236-248$.

Li, B.; Qiu, J., Jayakannan, M., Xu, B., Li, Y., Mayo, G. M., Tester, M., Gilliham, M., Roy, S. J. 2017. AtNPF2.5 Modulates Chloride $\left(\mathrm{Cl}^{-}\right)$Efflux from Roots of Arabidopsis thaliana. Front. Plant Sci 7, 2013.

Li, Kun Liu, Yong Hu, Dongping Li, and Luan, S. 2008. Single mutations convert an outward $\mathrm{K}^{+}$channel into an inward $\mathrm{K}^{+}$channel. Proc Natl Acad Sci U S A. 105(8):2871-2876. 
Li, L., He, Z., Pandey, G.K., Tsuchiya, T., and Luan, S. 2002. Functional Cloning and Characterization of a Plant Efflux Carrier for Multidrug and Heavy Metal Detoxification. Journal of Biological Chemistry 277:5360-5368.

Li, N., Chen, S., Zhou, X., Li, C., Shao, J., Wang, R., Fritz, E., Hüittermann, A., and Polle, A. 2008. Effect of $\mathrm{NaCl}$ on photosynthesis, salt accumulation and ion compartmentation in two mangrove species, Kandelia candel and Bruguiera gymnorhiza. Aquatic Botany 88:303-310.

Li, N., Xu, R., Duan, P., and Li, Y. 2018. Control of grain size in rice. Plant Reproduction 31(3):237-251.

Li, Y., Fan, C., Xing, Y., Jiang, Y., Luo, L., Sun, L., Shao, D., Xu, C., Li, X., and Xiao, J. 2011. Natural variation in GS5 plays an important role in regulating grain size and yield in rice. Nature Genetics 43(12):1266-1269.

Li, Y.Y., Shen, A., Xiong, W., Sun, Q.L., Luo, Q., Song, T., Li, Z.L., and Luan, W.J. 2016. Overexpression of OsHox32 Results in Pleiotropic Effects on Plant Type Architecture and Leaf Development in Rice. Rice (N Y) 9:46.

Liu L , Tong H , Xiao Y, et al. 2015. Activation of Big Grain1 significantly improves grain size by regulating auxin transport in rice. Proceedings of the National Academy of ences of the United States of America 112(35):11102.

Liu, and Luan. 2001. Internal aluminum block of plant inward $\mathrm{K}^{+}$channels. Plant Cell 13(6):1453-1465.

Livak, K.J., and Schmittgen, T.D. 2001. Analysis of relative gene expression data using real-time quantitative PCR and the 2(-Delta Delta C(T)) Method. Methods 25:402-408.

Magalhaes, J.V., Liu, J., Guimarães, C.T., Lana, U.G.P., and Kochian, L.V. 2007. A gene in the multidrug and toxic compound extrusion (MATE) family confers aluminum tolerance in sorghum. Nature Genetics 39:1156-1161.

Mao H, S.S., Yao J, Wang C, Yu S, Xu C, Li X, Zhang Q. 2010. Linking differential domain functions of the GS3 protein to natural variation of grain size in rice. Proceedings of the National Academy of Sciences of the United States of America 107:19579-19584. 
Marinova, K., Pourcel, L., Weder, B., Schwarz, M., Barron, D., Routaboul, J.-M., Debeaujon, I., and Klein, M. 2007. The Arabidopsis MATE Transporter TT12 Acts as a Vacuolar Flavonoid/ $\mathrm{H}^{+}$-Antiporter Active in Proanthocyanidin Accumulating Cells of the Seed Coat. Plant Cell 19:2023-2038.

Maron, L.G., Piñeros, M.A., Guimarães, C.T., Magalhaes, J.V., and Kochian, L.V. 2009. Two functionally distinct members of the MATE (multi-drug and toxic compound extrusion) family of transporters potentially underlie two major aluminum tolerance QTLs in maize. Plant Journal 61:728-740.

Metzler, D.E. 1979. Biochemistry: The Chemical Reactions of Living Cells; Academic Press: New York, NY, USA.

Meyer, S., Mumm, P., Imes, D., Endler, A., Weder, B., Al-Rasheid, K.A.S., Geiger, D., Marten, I., Martinoia, E., Hedrich, R. 2010. AtALMT12 represents an R-type anion channel required for stomatal movement in Arabidopsis guard cells. Plant J 63, 1054-1062.

Morita, Y. 1998. NorM, a putative multidrug efflux protein, of Vibrio parahaemolyticus and its homolog in Escherichia coli. Antimicrob Agents Chemother 42:1778.

Munemasa, S., Hauser, F., Park, J., Waadt, R., Brandt, B., Schroeder, J.I. 2015. Mechanisms of abscisic acid-mediated control of stomatal aperture. Curr. Opin. Plant Biol 28, 154-162.

Na, L., and Li, Y. 2015. Maternal control of seed size in plants. Journal of Experimental Botany 66(4):1087-1097.

Nguyen, C.T., Agorio, A., Jossier, M., Depre, S., Thomine, S., Filleur, S. 2016. Characterization of the Chloride Channel-Like, AtCLCg, Involved in Chloride Tolerance in Arabidopsis thaliana. Plant Cell Physiol 57, 764-775.

Olivier, V., Susana, R., Pere, M., and David, B. 2003. An enhanced transient expression system in plants based on suppression of gene silencing by the p19 protein of tomato bushy stunt virus. Plant Journal 33(5):949-956.

Qiu, J., Henderson, S.W., Tester, M., Roy, S.J., Gilliham, M. 2017. SLAH1, a homologue of the slow type anion channel SLAC1, modulates shoot $\mathrm{Cl}^{-}$ 
accumulation and salt tolerance in Arabidopsis thaliana. J. Exp. Bot 68, 4495-4505.

Randall, S.K., and Sze, H. 1986. Properties of the partially purified tonoplast $\mathrm{H}^{+}$-pumping ATPase from oat roots. J Biol Chem. 261:1364-1371.

Raven, J.A. 2017. Chloride: Essential micronutrient and multifunctional beneficial ion. J. Exp. Bot 68, 359-367.

Rognes, S.E. 1980. Anion regulation of lupin asparagine synthetase-Chloride activation of the glutamine-utilizing reactions. Phytochemistry 19, 2287-2293.

Sasaki, T., Mori, I.C., Furuichi, T., Munemasa, S., Toyooka, K., Matsuoka, K., Murata, Y., Yamamoto, Y. 2010. Closing Plant Stomata Requires a Homolog of an Aluminum-Activated Malate Transporter. Plant Cell Physiol 51, 354-365.

Shiomi, N., Fukuda, H., Murata, K., and Kimura, A. 1995. Improvement of S-adenosylmethionine production by integration of the ethionine-resistance gene into chromosomes of the yeast Saccharomyces cerevisiae. Applied Microbiology \& Biotechnology 42(5):730-733.

Shomura, A., Izawa, T., Ebana, K., Ebitani, T., Kanegae, H., Konishi, S., and Yano, M. 2008. Deletion in a gene associated with grain size increased yields during rice domestication. Nature Genetics 40:1023-1028.

Song, X.J., Huang, W., Shi, M., Zhu, M.Z., and Lin, H.X. 2007. A QTL for rice grain width and weight encodes a previously unknown RING-type E3 ubiquitin ligase. Nature Genetics 39:623-630.

Teakle NL, Tyerman SD. 2010. Mechanisms of $\mathrm{Cl}^{-}$transport contributing to salt tolerance. Plant Cell Environ 33(4):566-89.

Tian, W., Hou, C., Ren, Z., Pan, Y., Jia, J., Zhang, H., Bai, F., Zhang, P., Zhu, H., and He, Y et al. 2015. A molecular pathway for $\mathrm{CO}_{2}$ response in Arabidopsis guard cells. Nature Communications 6:6057.

Waadt, R., and Kudla, J. 2008. In Planta Visualization of Protein Interactions Using Bimolecular Fluorescence Complementation (BiFC). CSH Protoc pdb prot 4995. 
Waadt, R., Schmidt, L.K., Lohse, M., Hashimoto, K., Bock, R., and Kudla, J. 2008. Multicolor bimolecular fluorescence complementation reveals simultaneous formation of alternative CBL/CIPK complexes in planta. Plant J 56:505-516.

Wang, L., Bei, X., Gao, J., Li, Y., Yan, Y., and Hu, Y. 2016. The similar and different evolutionary trends of MATE family occurred between rice and Arabidopsis thaliana. BMC Plant Biology 16:207.

Wege, S., Gilliham, M., Henderson, S.W. 2017. Chloride: Not simply a 'cheap osmoticum', but a beneficial plant macronutrient. J. Exp. Bot 68, 3057-3069.

White, P.J.,Broadley, M.R. 2001. Loride in soils and its uptake and movement within the plant: A review. Ann. Bot 88, 967-988.

Xu, G.H., Magen, H., Tarchitzky, J., Kafkafi, U. 2000. Advances in chloride nutrition of plants. In Advances in Agronomy; Sparks, D.L., Ed.; Academic Press: San Diego, CA, USA, Volume 68, pp. 97-150.

Yokosho, K., Yamaji, N., and Jian, F.M. 2011. An Al-inducible MATE gene is involved in external detoxification of $\mathrm{Al}$ in rice. Plant Journal for Cell \& Molecular Biology 68:1061-1069.

Yokosho, K., Yamaji, N., Kashino-Fujii, M., and Ma, J.F. 2016. Retrotransposon-mediated aluminum tolerance through enhanced expression of the citrate transporter OsFRDL4. Plant Physiology 172(4):2327-2336.

Yokosho, K., Yamaji, N., Ueno, D., Mitani, N., and Ma, J.F. 2009. OsFRDL1 is a citrate transporter required for efficient translocation of iron in rice. Plant Physiology 149(1):297-305.

Yoo, S.-D., Cho, Y.-H., and Sheen, J. 2007. Arabidopsis mesophyll protoplasts: a versatile cell system for transient gene expression analysis. Nature Protocols 2:1565-1572.

Zhang, H., Zhao, F.G., Tang, R.J., Yu, Y., and Luan, S. 2017. Two tonoplast MATE proteins function as turgor-regulating chloride channels in Arabidopsis. Proc Natl Acad Sci U S A 114(10):E2036-E2045.

Zhang, H., Zhu, H., Pan, Y., Yu, Y., Luan, S., and Li, L. 2014. A DTX/MATE-Type Transporter Facilitates Abscisic Acid Efflux and Modulates 
ABA Sensitivity and Drought Tolerance in Arabidopsis. Molecular Plant 7:1522-1532.

Zhang, J.L., Flowers, T.J., Wang, S.M. 2010. Mechanisms of sodium uptake by roots of higher plants. Plant Soil 326, 45-60.

Zhang, Y., Su, J., Duan, S., Ao, Y., Dai, J., Liu, J., Wang, P., Li, Y., Liu, B., Feng, D., et al. 2011. A highly efficient rice green tissue protoplast system for transient gene expression and studying light/chloroplast-related processes. Plant Methods 7:30.

Zonia, L., Cordeiro, S., Tupy, J., Feijo, J.A. 2002. Oscillatory chloride efflux at the pollen tube apex has a role in growth and cell volume regulation and is targeted by inositol 3,4,5,6-tetrakisphosphate. Plant Cell 14, 2233-2249.

Zuo, J., and Li, J. 2014. Molecular Genetic Dissection of Quantitative Trait Loci Regulating Rice Grain Size. Annual Review of Genetics 48:99-118. 


\section{Figures and Legends}

a

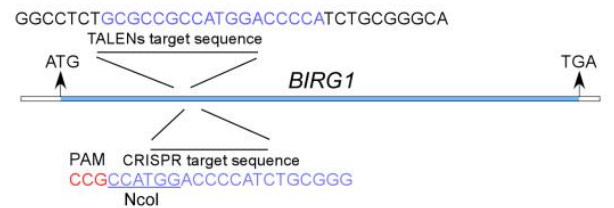

WT ACCGGCCIRG1-TALENS birg1-1 ACCGGCCTCTGCGCCG ........- CCCCATCTGCGGG BIRG1-CRISPR/Cas9 WT GGCCTCTGCGCCGCCATGGACCCCATCTGCGGGCA birg1-2 GGCCTCTGCGCCGCCA-GGACCCCATCTGCGGGCA

b

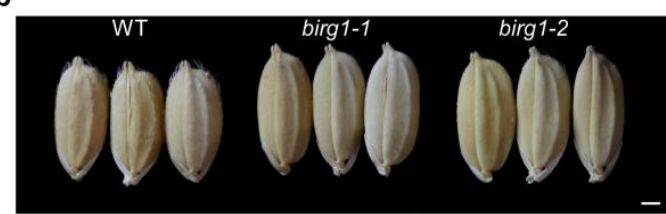

c

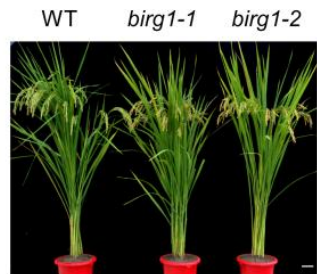

e

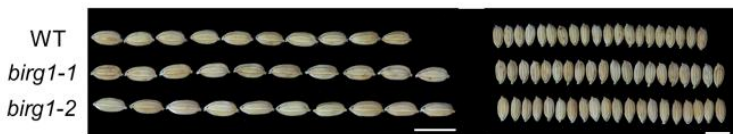

f

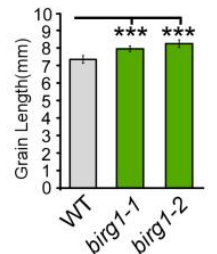

d

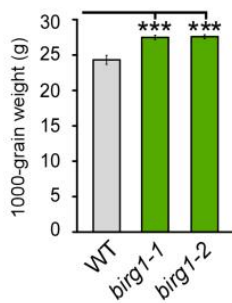

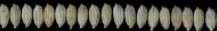

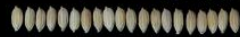

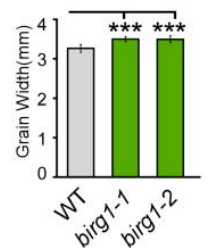

Fig. 1 Knockout of BIRG1 increases grain size in rice. (a) Characterization of birg1-1 and birg1-2 generated by TALENs and CRISPR/Cas9 techniques, respectively. (b) Grain morphology of the WT, birg1-1 and birg1-2. (Scale bar=1 mm). (c) Gross morphology of 120 days-old plants of WT, birgl-1 and birgl-2 grown in a paddy field. (Scale bar=4 cm). (d) Statistical data of 1,000-grain weight in the WT, birg 1-1 and birg1-2. $(\mathrm{n}=3)$. (e) Comparative observation on grain arrangement of the WT, birg 1-1 and birg1-2 (Scale bar=1 cm). (f) Statistical data of the grain length, grain width, and grain thickness in the WT, birgl-1 and birg1-2. Rice plants were grown in a paddy field located in Lang Fang, He Bei, China, where the Cl- concentration is $0.11 \pm 0.06 \mathrm{~g} \mathrm{~kg}^{-1}$, under natural conditions. Means $\pm \mathrm{SD}$ are given in $\mathrm{F}(\mathrm{n}=10), p$ value (Student's $t$-test), $* p<0.05, * * p<0.01$ and $* * * p<0.001$. 
a

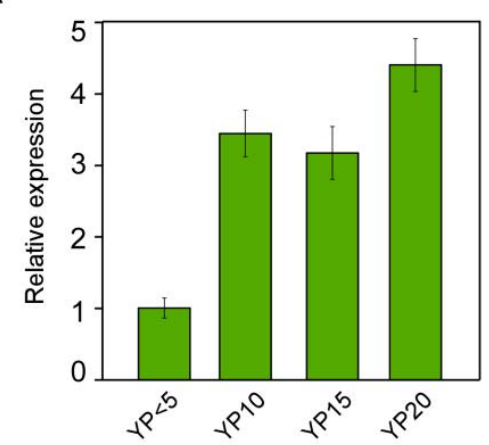

b

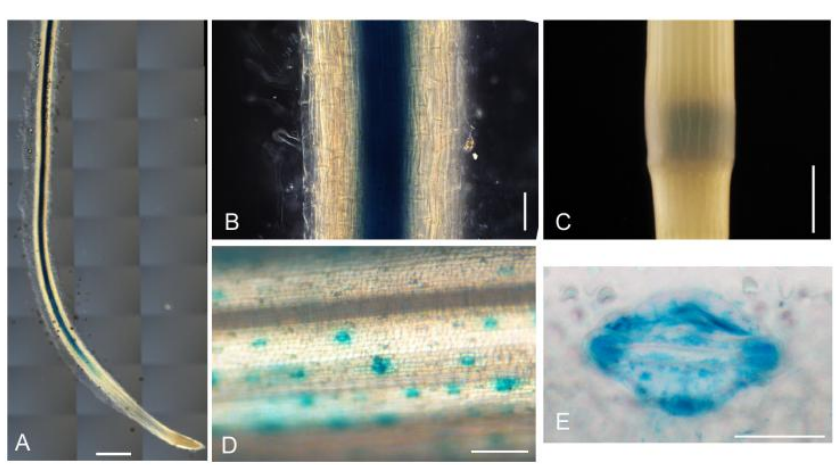

C
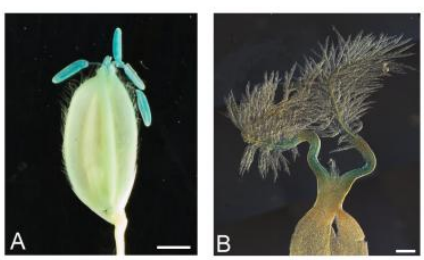

AUTO

d

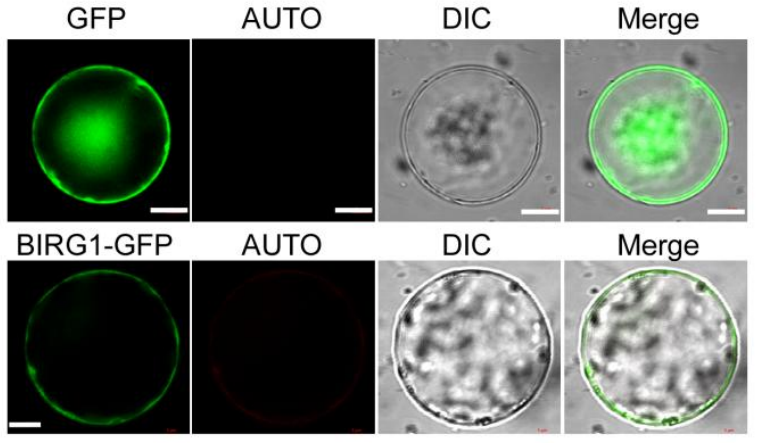

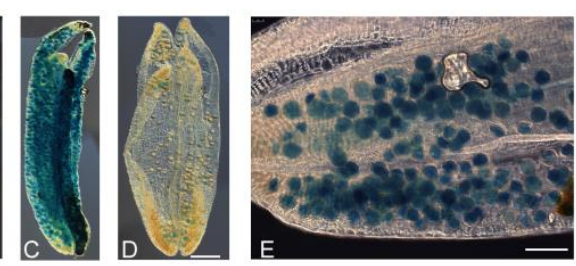

e GFP
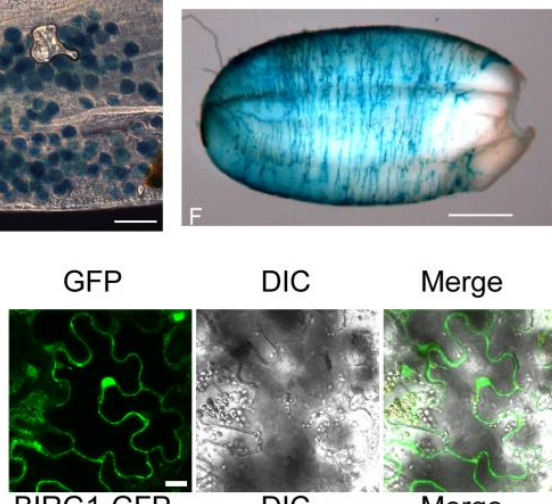

DIC Merge
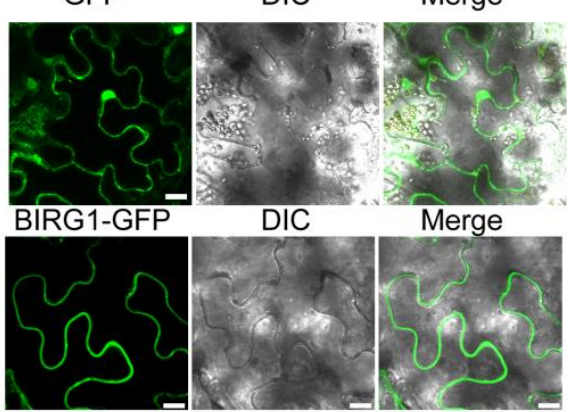

Fig. 2 Tissue-specific expression and subcellular localization of BIRG1. (a) Expression of BIRG1 in different lengths of developing young panicles (indicated as numbers, cm). (b) Expression of BIRG1::GUS in young roots (A and B) (Scale bar, $\mathrm{a}=0.1 \mathrm{~cm}, \mathrm{~b}=0.05 \mathrm{~cm})$, culm node $(\mathrm{C})($ Scale bar, $1 \mathrm{~cm})$, leaf (D) $($ Scale bar, $1 \mathrm{~cm})$ and guard cells (E) (Scale bar, $8 \mu \mathrm{m}$ ). (c) Expression of BIRG1::GUS in spikelet hulls (A) (Scale bar, $0.2 \mathrm{~cm}$ ), pistil (B) (Scale bar, $0.5 \mathrm{~mm}$ ), anther (C and D) (Scale bar, $1 \mathrm{~mm}$ ), pollens (E) (Scale bar, $1 \mathrm{~mm}$ ) and seed (F) (Scale bar, $1 \mathrm{~mm}$ ). (d) Rice green tissue protoplasts transformed with $35 \mathrm{~S}::$ BIRG $1-G F P$ and $35 \mathrm{~S}:: G F P$. Scale bar $=5 \mu \mathrm{M}$. (e) Tobacco epidermal leaf cells transiently transformed with 35S:: BIRG1-GFP and 35S::GFP. Scale bar $=50 \mu \mathrm{m}$. 


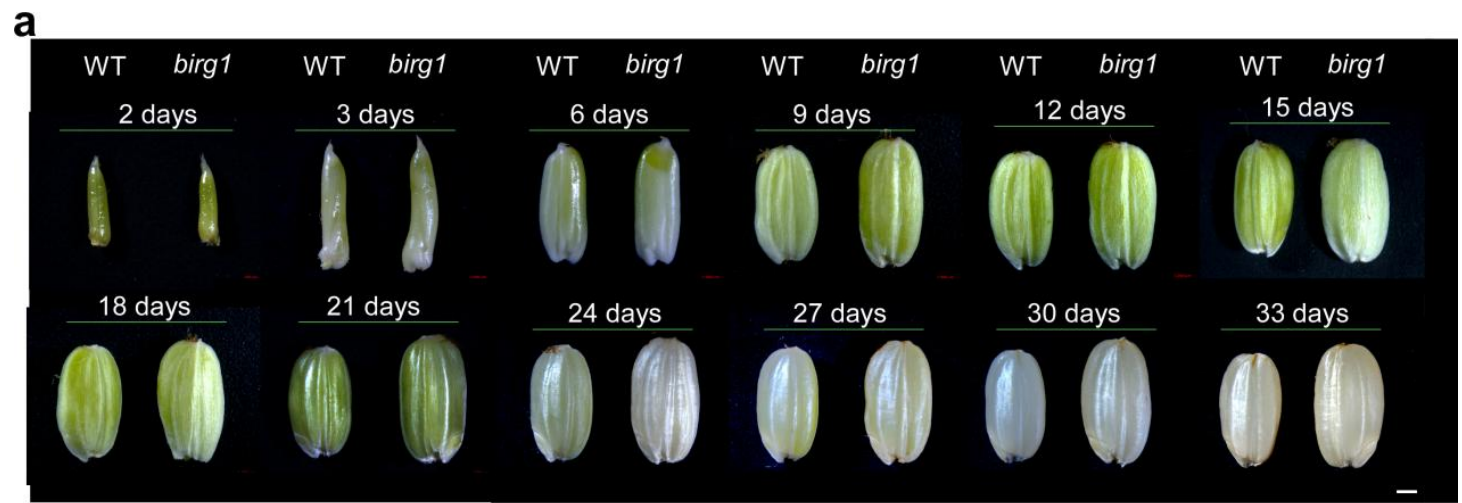

b
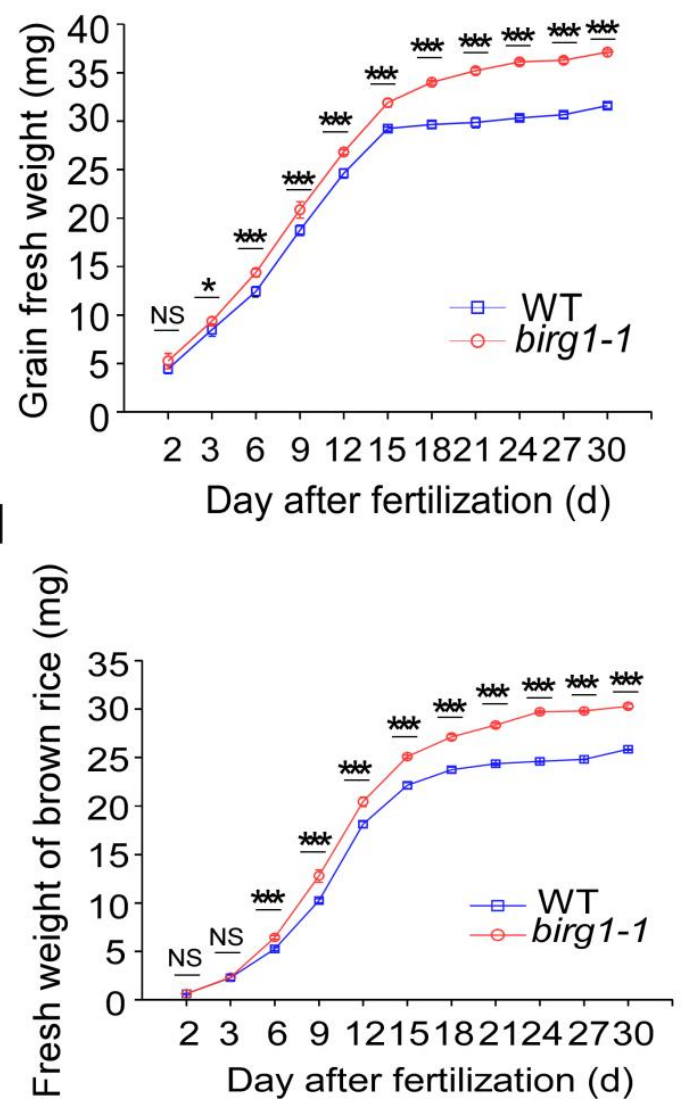

C

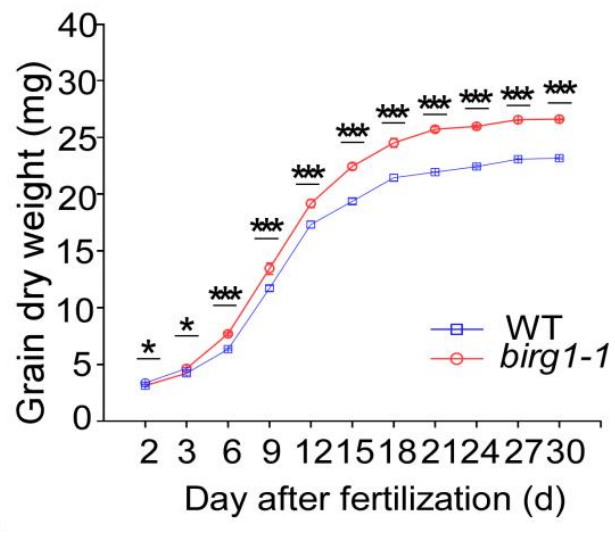

छे 30

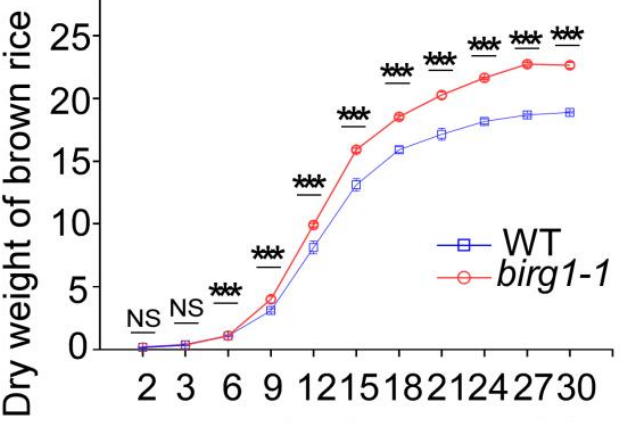

Day after fertilization (d)

Fig. 3 The birgl mutant shows accelerated grain filling rate. (a) Developing WT and birg $1-1$ seeds in 2, 3, 6, 9, 12, 15, 18, 21, 24, 27, 30 and 33 DAP were photographed. Bars $=1 \mathrm{~mm}$. (b) Time-course of the WT and birgl-1 grain fresh weight $(\mathrm{n}=100$ grains for each point). (c) Time-course of the WT and birg1-1 grain dry weight (n $=100$ grains for each point). (d) Time-course of the WT and birgl-1 brown rice fresh weight ( $\mathrm{n}=100$ grains for each point). (e) Time-course of the WT and birgl-1 brown rice dry weight ( $\mathrm{n}=100$ grains for each point). WT, Line with blue diamonds; birg 1-1, Line with red circle. Means $\pm \mathrm{SD}$ are given in B-E $\left(\mathrm{n}=5^{*} 20\right), P$ Value based on Student's $t$-test. NS means No Significance, $* p<0.05, * * p<0.01$ and $* * * p<0.001$. 
a

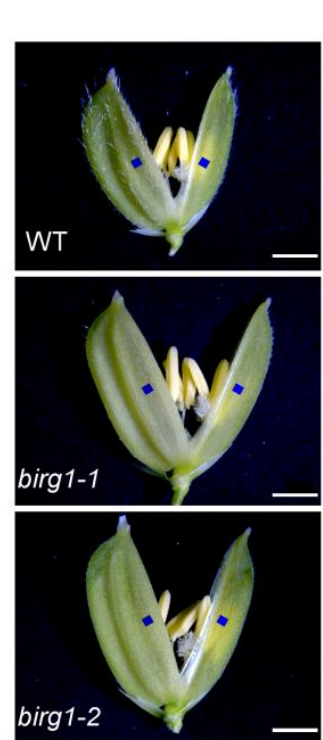

d

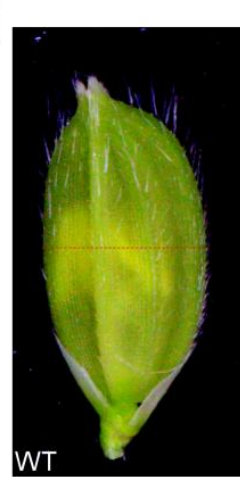

f

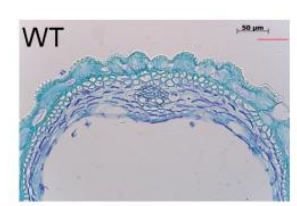

birg1-1

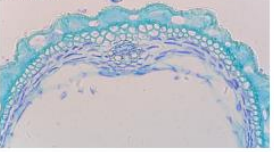

birg1-2

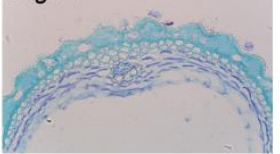

lemma
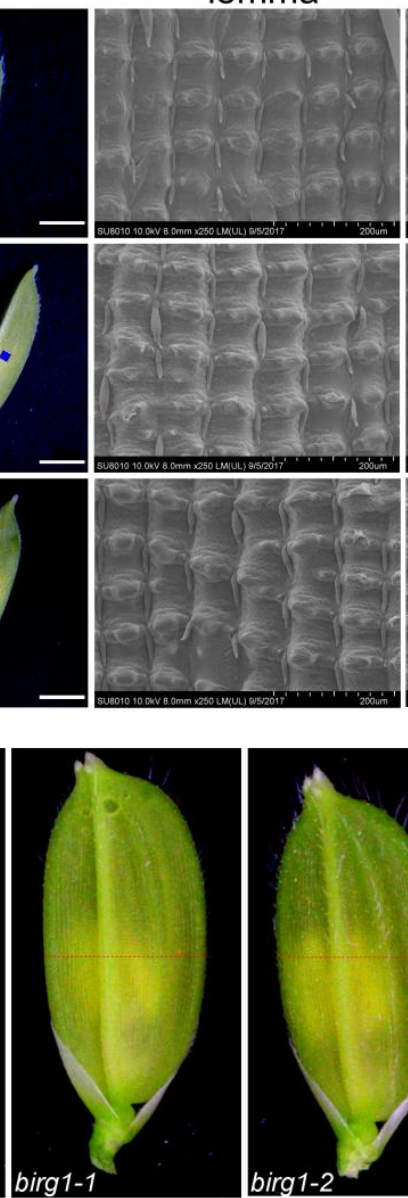

g

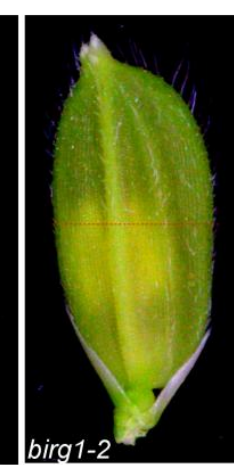

birg1-2

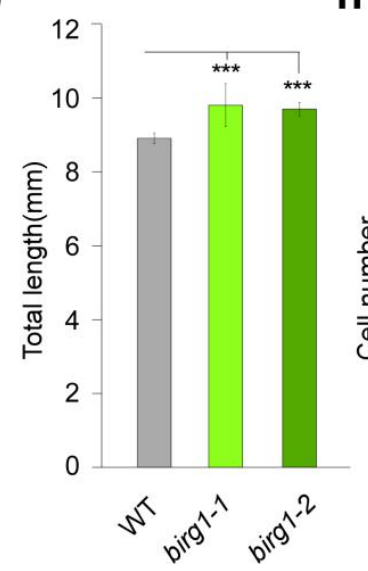

palea

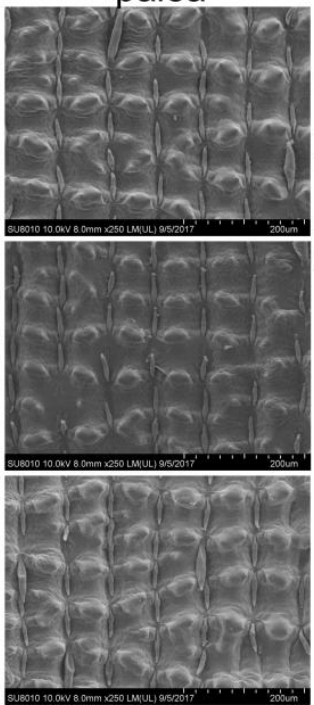

e

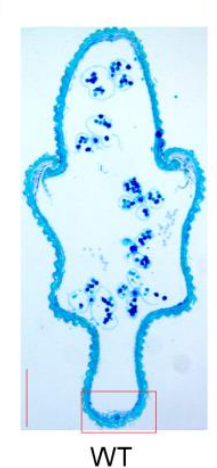

WT

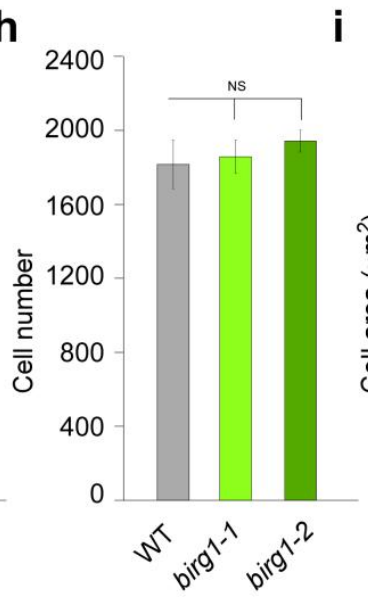

i

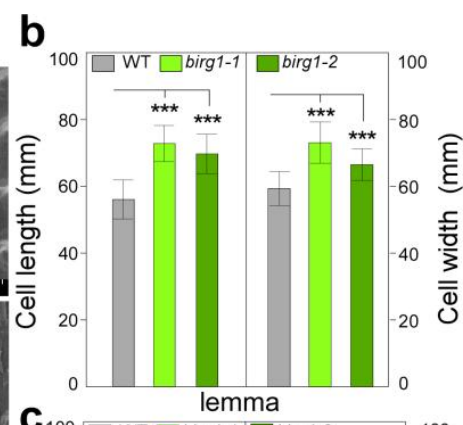

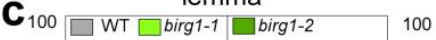

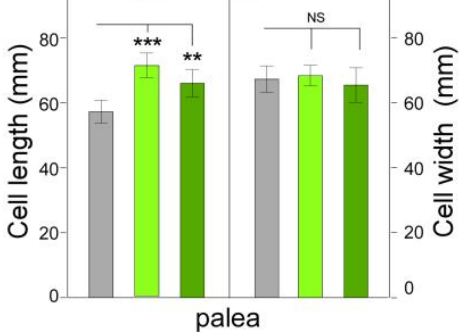

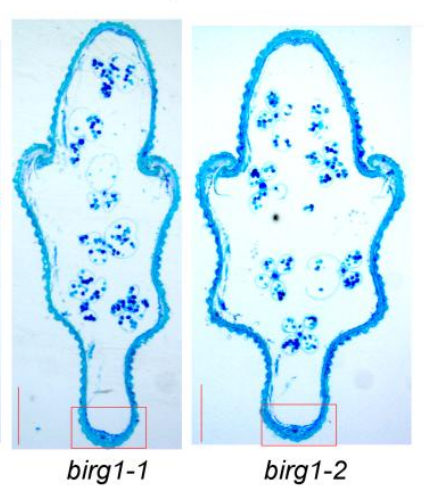

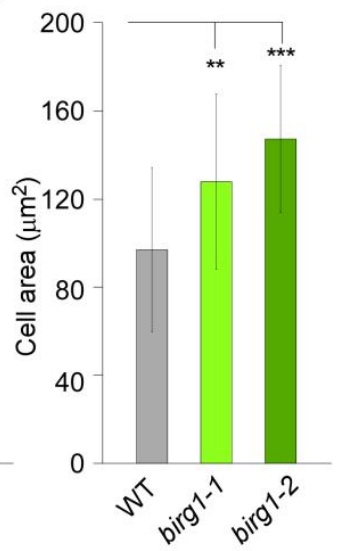

Fig. 4 Increased grain size in birgl mutants is caused by increased cell expansion in the spikelet hulls. (a) Scanning electron and light microscope photographs of the outer surfaces of young spikelet hulls of WT, birg 1-1 and birg1-2. Scale bar, $1 \mathrm{~mm}$ for the whole spikelets and $200 \mu \mathrm{m}$ for lemma and palea. (b) Comparison analysis of cell length and width in outer surfaces of lemma $(n=20)$. Scale bar=500 $\mu$ m. (c) Comparison analysis of cell length and width in outer surfaces of palea $(n=20)$. Scale 
bar $=100 \mu \mathrm{m}$. (d) Young spikelet hulls of WT, birgl-1 and birg1-2. The red line indicates the position of the cross-section. (e) Cross-sections of spikelet hulls. Scale bar=0.5 mm. (f) Magnified view of the cross-section area boxed in (e). Scale bar=50 $\mu \mathrm{m}$. (g) Comparison analysis of the total cell length in the outer parenchyma layer (n = 5). (h) Comparison analysis of the total cell number in the outer parenchyma layer $(n=5)$. (i) Comparison analysis of the cell area in the outer parenchyma layer $(n=5)$. All data are means \pm SD. Student's $t$-test was used to generate the $P$ values; ${ }^{*} p<0.05$, $* * p<0.01$ and $* * * p<0.001$.

a

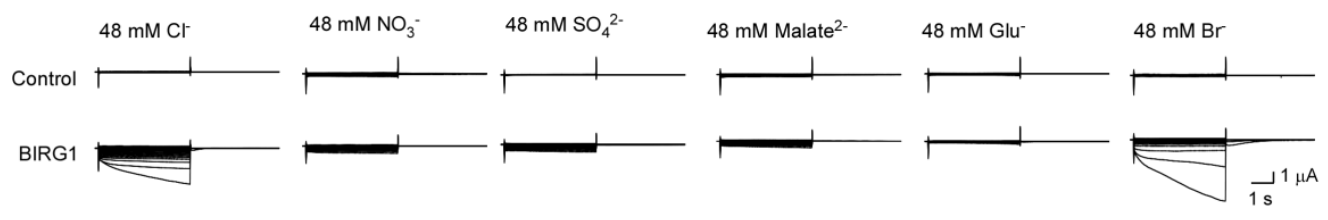

b

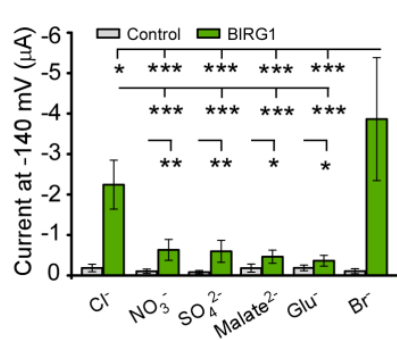

C

d

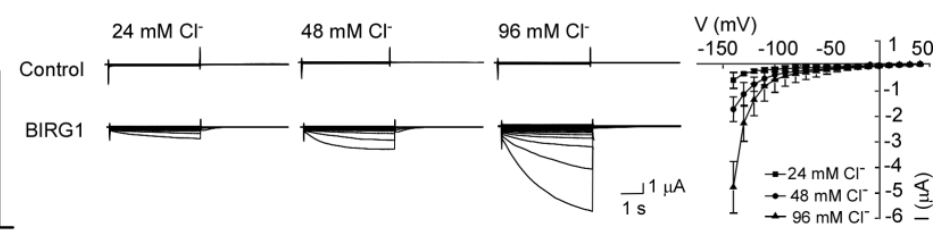

e

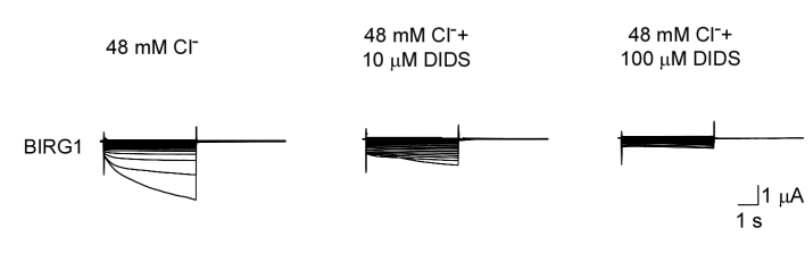

g

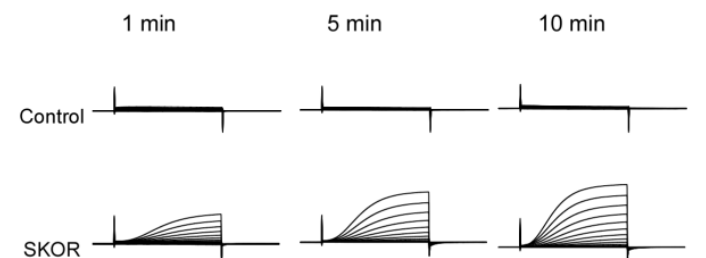

SKOR

i

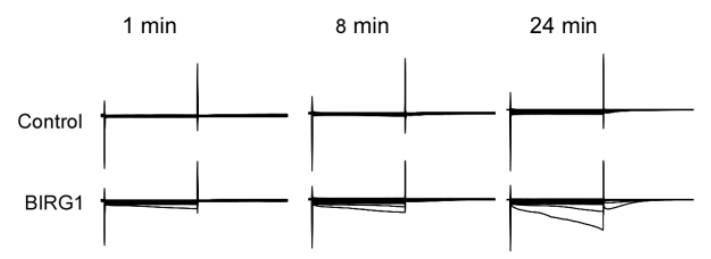

$32 \min$

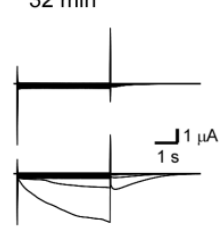

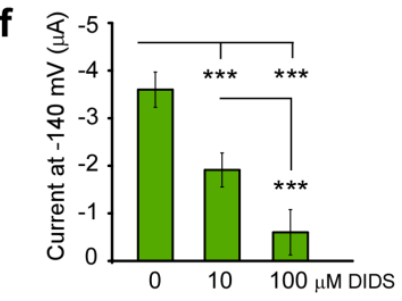

h - Control; 1 min
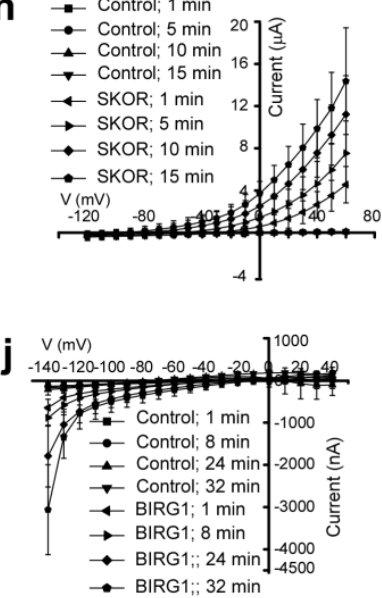

Fig. 5 BIRG1 mediates $\mathrm{Cl}^{-}$efflux in Xenopus ooctyes. (a) Typical whole-cell currents recorded by hyperpolarized pulses from oocytes injected with water ("Control”) or 
oocytes expressing BIRG1 perfused with a bath solution containing $48 \mathrm{mM} \mathrm{Cl}^{-}, \mathrm{NO}_{3}{ }^{-}$, $\mathrm{SO}_{4}{ }^{2-}, \mathrm{Malate}^{2-}, \mathrm{Br}^{-}$or $\mathrm{Glu}^{-}$. Voltage ramps of $4 \mathrm{~s}$ duration were applied to the membrane with a voltage ranging from -140 to $+40 \mathrm{mV}$. (b) Current amplitudes at $-140 \mathrm{mV}$ from multiple recordings as in (a). (c) The typical current traces generated by control oocytes injected with water or oocytes expressing BIRG1 bathed in a solution containing 24,48 or $96 \mathrm{mM}$ chloride with a voltage ranging from -140 to +40 $\mathrm{mV}$. (d) The current-voltage relationship was deduced as in (c). The data are mean \pm SD $(n=5)$. (e) Oocytes expressing BIRG1 were recorded in a solution containing 48 $\mathrm{mM} \mathrm{Cl}-$ plus 0,10 or $100 \mu \mathrm{M}$ DIDS. Voltage ranging from -140 to $+40 \mathrm{mV}$. (f) Current amplitudes at $-140 \mathrm{mV}$ in the presence of indicated concentrations of DIDS as in (e). (g) Typical whole-cell currents recorded from control oocytes or oocytes expressing SKOR perfused with standard ND96 solution. The currents were recorded at the time point indicated. Voltage ranging from -120 to $+60 \mathrm{mV}$ in $10 \mathrm{mV}$ increments. The holding potential was $-100 \mathrm{mV}$. (h) The current-voltage relationship was deduced as in (g). (i) Typical whole-cell currents recorded from control oocytes or oocytes expressing BIRG1 perfused with a modified $\mathrm{Cl}^{-}$-free ND96 (chloride was replaced with glutamate). The currents were recorded at the time point indicated. Voltage ranging from -140 to $+40 \mathrm{mV}$ in $10 \mathrm{mV}$ increments. (j) The current-voltage relationship was deduced as in (i). All data are mean $\pm \mathrm{SD}(\mathrm{n} \geq 5), p$ Value based on Student's $t$-test, * $p<0.05, * * p<0.01$ and $* * * p<0.001$. 
a

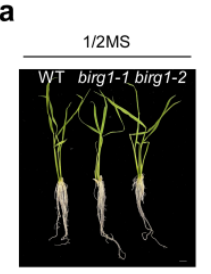

e

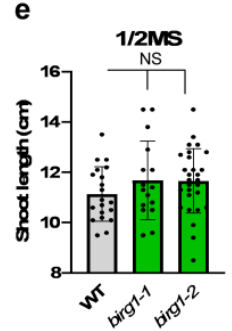

$1 / 2 \mathrm{MS}+100 \mathrm{mM} \mathrm{Cl}$
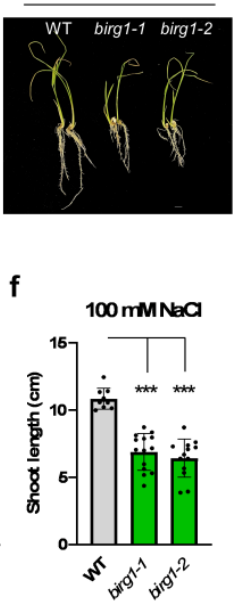

$1 / 2 \mathrm{MS}+150 \mathrm{mMCr}$

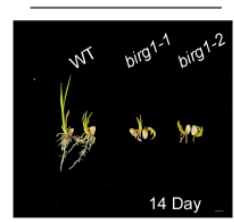

g $\mathbf{h}$

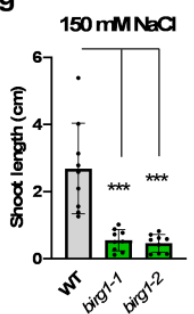

h
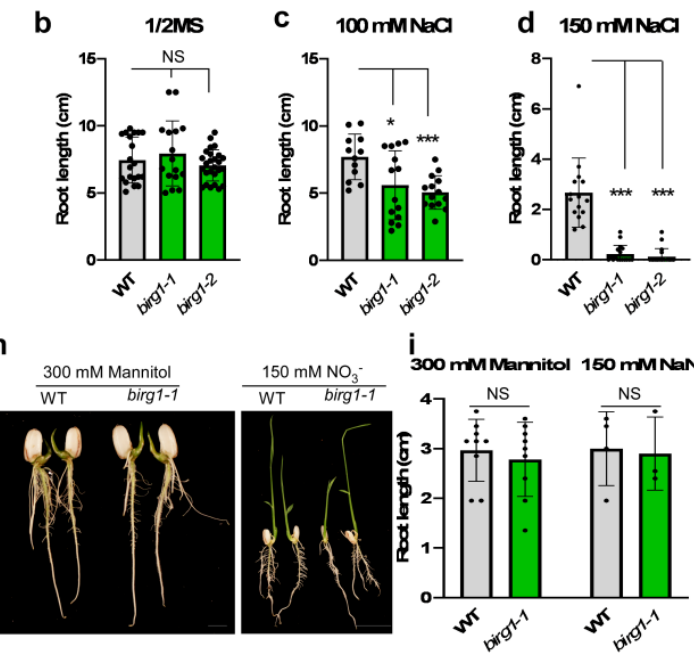

$\mathrm{i}$

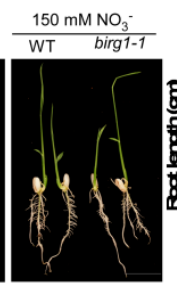
300 mMMarnitol $150 \mathrm{mMN}$ NaNOS

Fig. $6 \mathrm{NaCl}$ stress assays for seedlings in WT and birgl. (a) Seedling morphology of the WT, birgl-1, and birg1-2 grown on 1/2MS, 1/2MS+100 $\mathrm{mM} \mathrm{NaCl}$ and 1/2MS+150 mM NaCl for 14 days. (Scale bar=1 cm). (b) The root length of WT, birg 1-1, and birg 1-2 grown on 1/2MS, $\mathrm{n} \geq 15$. (c) The root length of WT, birg 1-1, and birg1-2 grown on 1/2MS+100 $\mathrm{mM} \mathrm{NaCl}, \mathrm{n} \geq 15$. (d) The root length of WT, birg1-1, and birgl-2 grown on $1 / 2 \mathrm{MS}+150 \mathrm{mM} \mathrm{NaCl}, \mathrm{n} \geq 15$. (e) The shoot length of $\mathrm{WT}$, birg 1-1, and birg 1-2 grown on 1/2MS, $\mathrm{n} \geq 15$. (f) The shoot length of WT, birg 1-1, and birgl-2 grown on $1 / 2 \mathrm{MS}+100 \mathrm{mM} \mathrm{NaCl}, \mathrm{n} \geq 15$. (g) The shoot length of WT, birg1-1, and birgl-2 grown on 1/2MS+150 mM NaCl, $\mathrm{n}>9$. (h) Seedling morphology of the WT, birglgrown on 1/2MS+300 mM Mannitol, and 1/2MS+150 mM NaNO${ }_{3}$. (Left Scale bar=1 $\mathrm{cm}$ and right $\mathrm{Scale}$ bar=2 $\mathrm{cm}$ ). (i) The root length of WT, birgl grown on 1/2MS+300 mM Mannitol, and 1/2MS+150 mM NaNO $3 . n>3$. The data are mean \pm SD, Student's $t$-test was used to generate the $P$ values, $* p<0.05$, $* * p<0.01$ and $* * * p$ $<0.001$. 

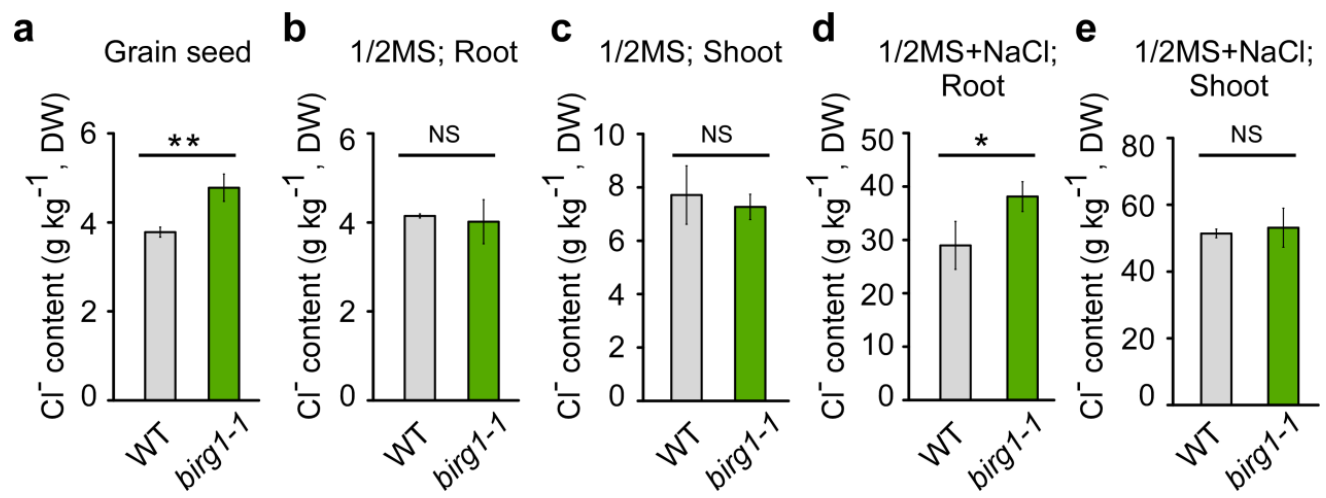

Fig. 7 Chloride content of WT and birgl mutant. (a) Chloride content of WT and birgl grain. The rice plants were grown in a paddy field located in Lang Fang, He Bei, China, $\mathrm{n}=3$. ( $\mathrm{b}$ and c) Chloride content of the seedling root and shoot of WT and birg1 grown on 1/2MS. (d and e) Chloride content of the seedling root and shoot of WT and birg1 grown on 1/2MS plus $100 \mathrm{mM} \mathrm{NaCl}$. 14-day-old seedling root and shoot were separated, and 6 roots or shoots were collected as one sample, $n=3$. The data are mean $\pm \mathrm{SD}$, Student's $t$-test was used to generate the $p$ values, $* p<0.05$, ** $p<0.01$ and $* * *$ $p<0.001$.

\section{Supporting Information}
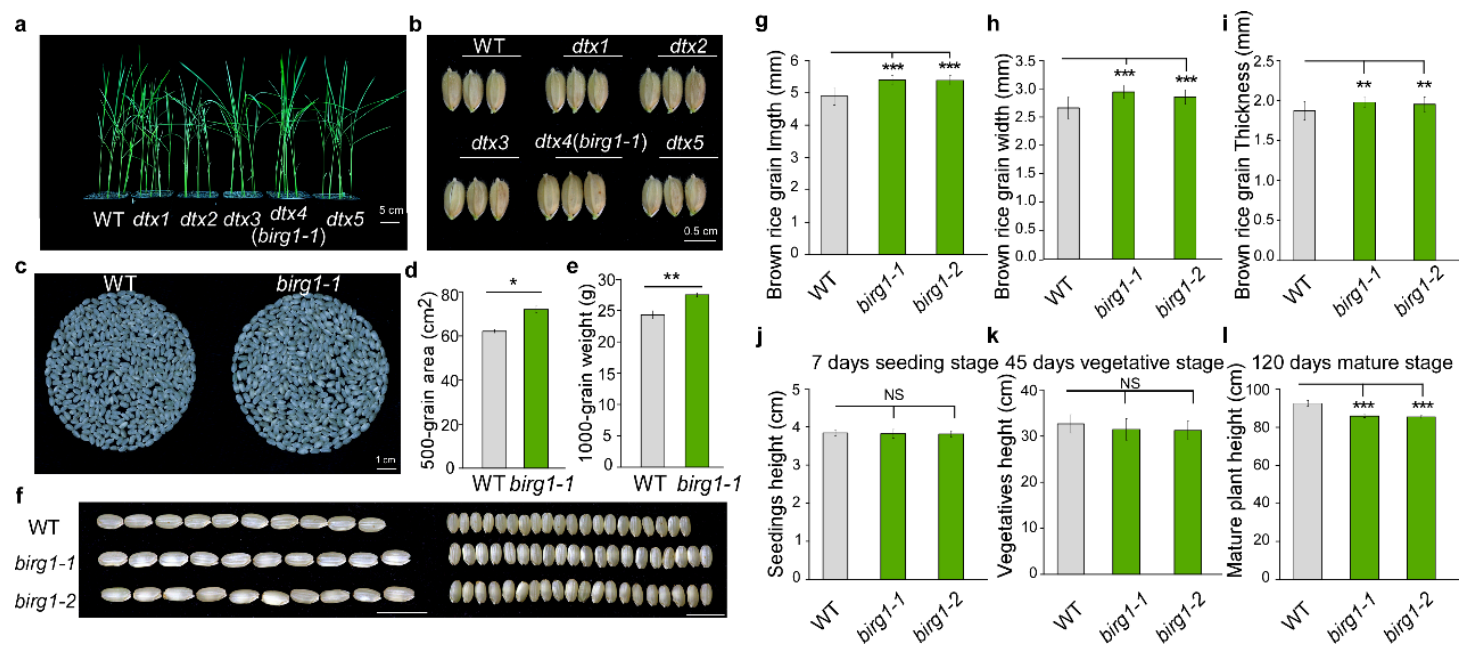

Fig. S1. Phenotypes of $d t x$ mutants. (a) Seeding morphology of the WT and several $d t x$ mutants. The $d t x 4$ is named birg 1-1. (Scale bar=5 cm). (b) Grain size of the WT and five $d t x$ mutants. (Scale bar=0.5 cm). (c) Cover area of 500-grain in the WT and birg 1-1. (Scale bar=1cm). (d) Statistical area of 500-grain in the WT and birg1-1. (e) Statistical data of 1,000-grain weight in the WT and birgl-1. (f) Brown rice 
morphology of the WT, birg1-1 and birg1-2. Scale bars=1 cm. (g) Statistical data of grain length (j), grain width (h) and grain thickness (i) of the WT, birg1-1 and birgl-2. $\mathrm{n}=20$. (j) 7 days seeding height of the WT and $\operatorname{birg} 1-1$, $\operatorname{birg} 1-2$. $\mathrm{n}=5$. (k) 45 days vegetatives stage height of WT, birgl-1 and birgl-2, n=8. (1) 120 days mature stage height of the WT and birg1-1, birg1-2. $\mathrm{n}=5$. Data shown as means $\pm \mathrm{SD}, p$ Value based on Student's $t$-test, $* p<0.05, * * p<0.01$ and $* * * p<0.001$.

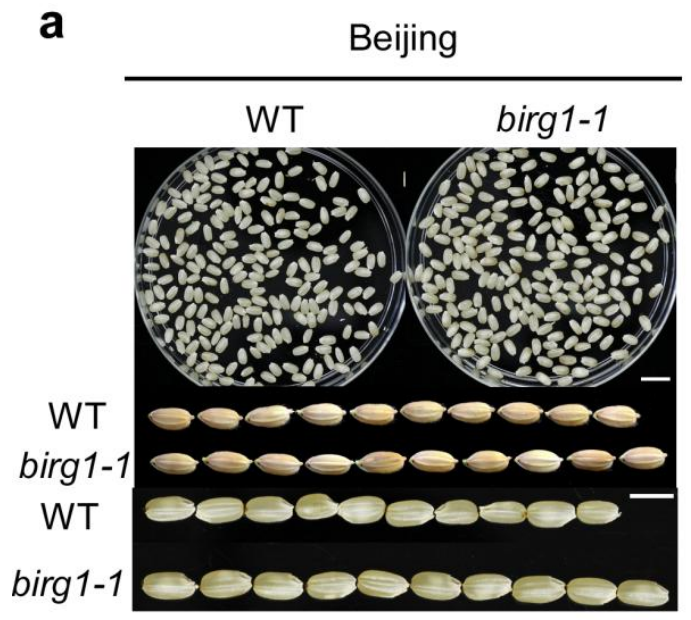

C

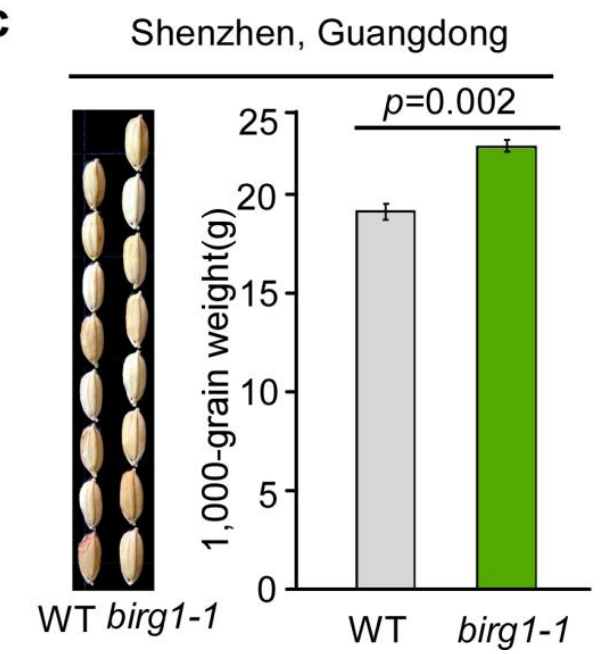

b Changsha, Hunan

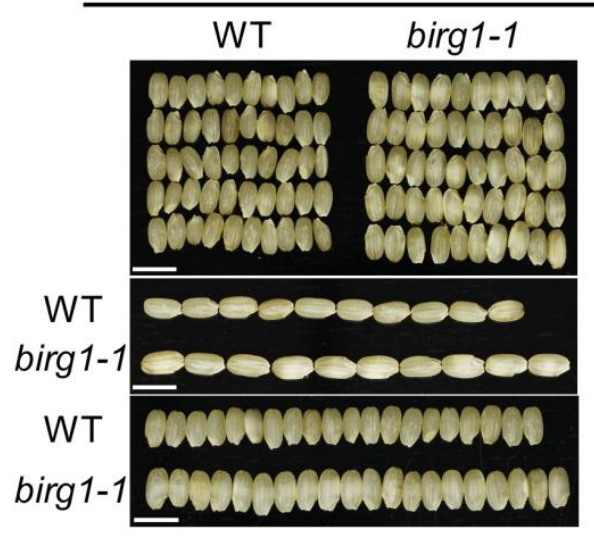

d

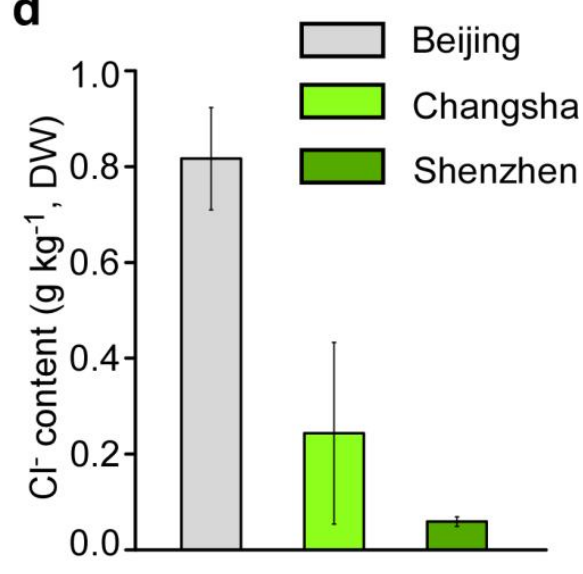

Fig. S2. Grain phenotype of WT and birgl mutant in different regions with varied $\mathrm{Cl}^{-}$ level. Grain size of WT and birgl grown in Beijing, the north of China (a), (Scale bar=1 cm, $0.5 \mathrm{~cm})$; Changsha, the middle of China (b) (Scale bar=0.5 cm); or Shenzhen, the south of China (c). The $\mathrm{Cl}^{-}$contents in soil from Beijing, Changsha and Shenzhen were measured $(\mathrm{d}), \mathrm{n}>=3$. Data are represented as mean \pm SD. $p$ Value based on Student's $t$-test. 

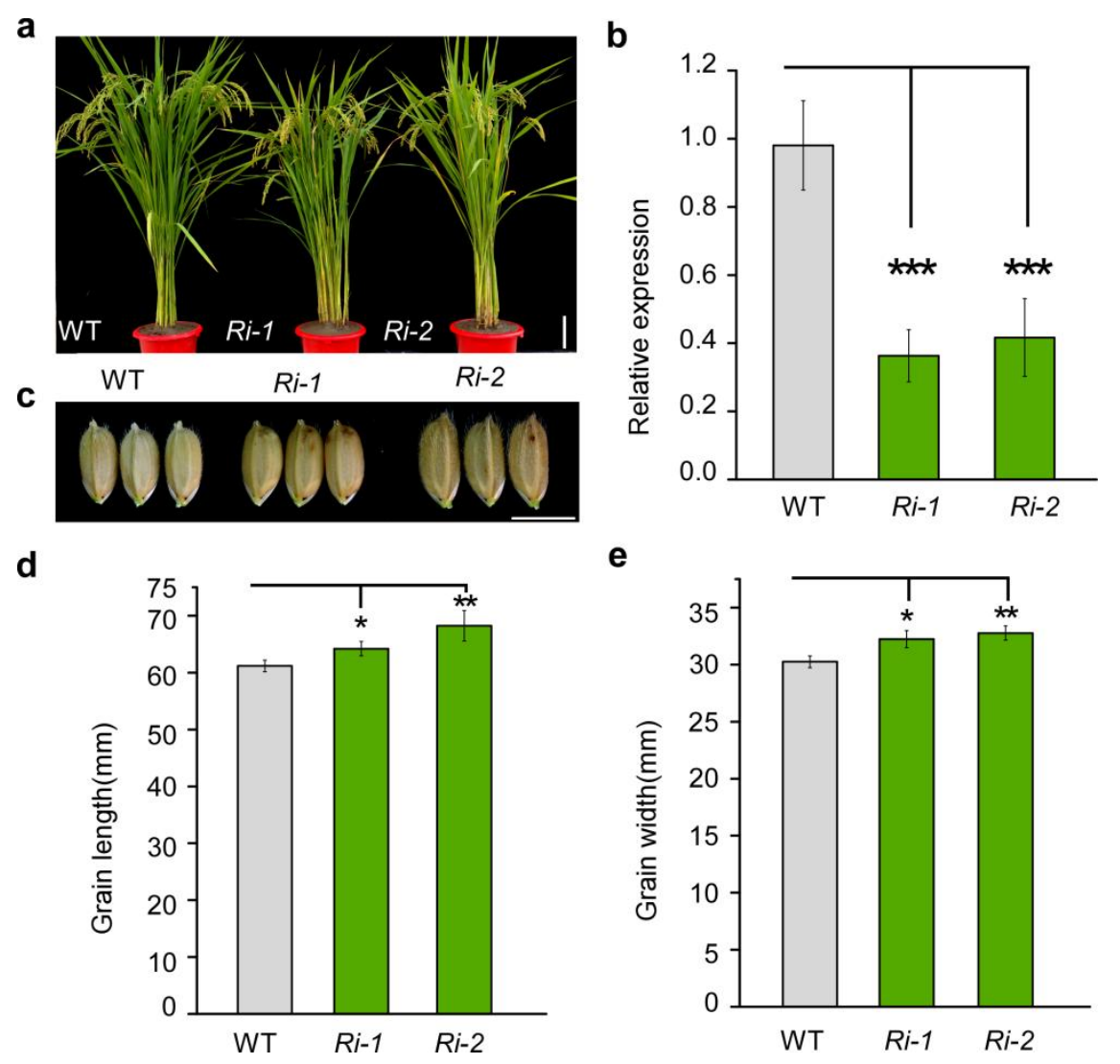

Fig. S3. The phenotypes of BIRG1-knockdown plants (Ris). (a) The morphology of the WT and Ris (Scale bars $=5 \mathrm{~cm}$ ). (b) The expression levels of BIRG1 in the WT, Ri-1 and $R i-2$ plants detected by qRT-PCR. (c) Grain size of the WT, Ri-land Ri-2 plants (Scale bars=0.5 cm). (d) Statistical data of the grain length of the WT, Ri-1 and Ri-2. (e) Statistical data of the grain width of the WT, $R i-1$ and $R i-2$, Means \pm SD are given in $\mathrm{D}$ and $\mathrm{E}(\mathrm{n}=10), P$ value (Student's $t$-test), $* p<0.05, * * p<0.01$ and $* * * p<0.001$. 

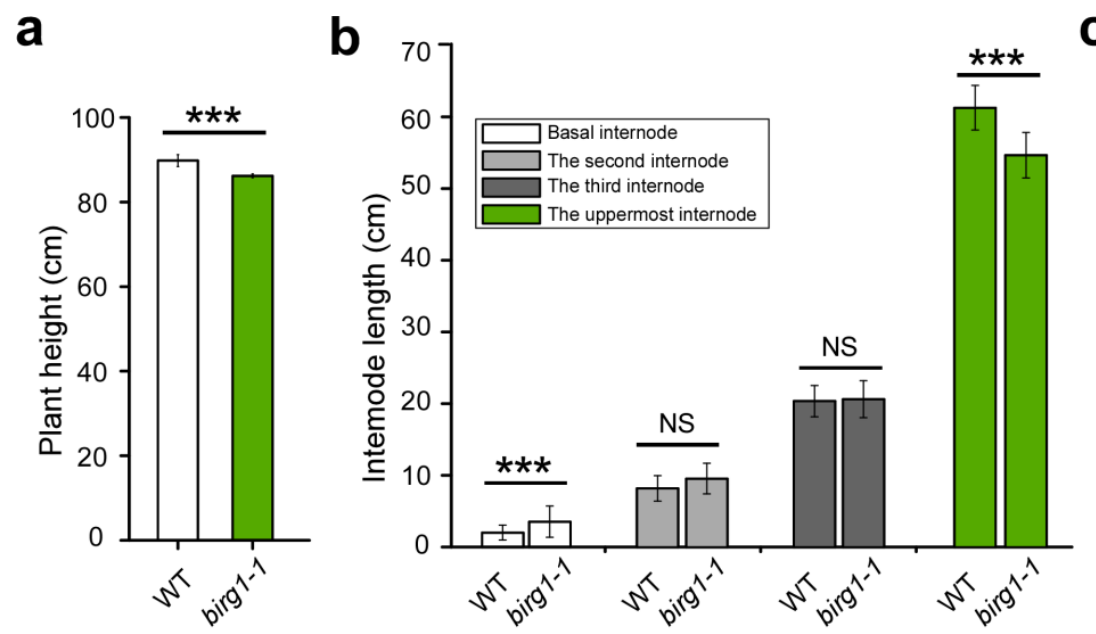

C
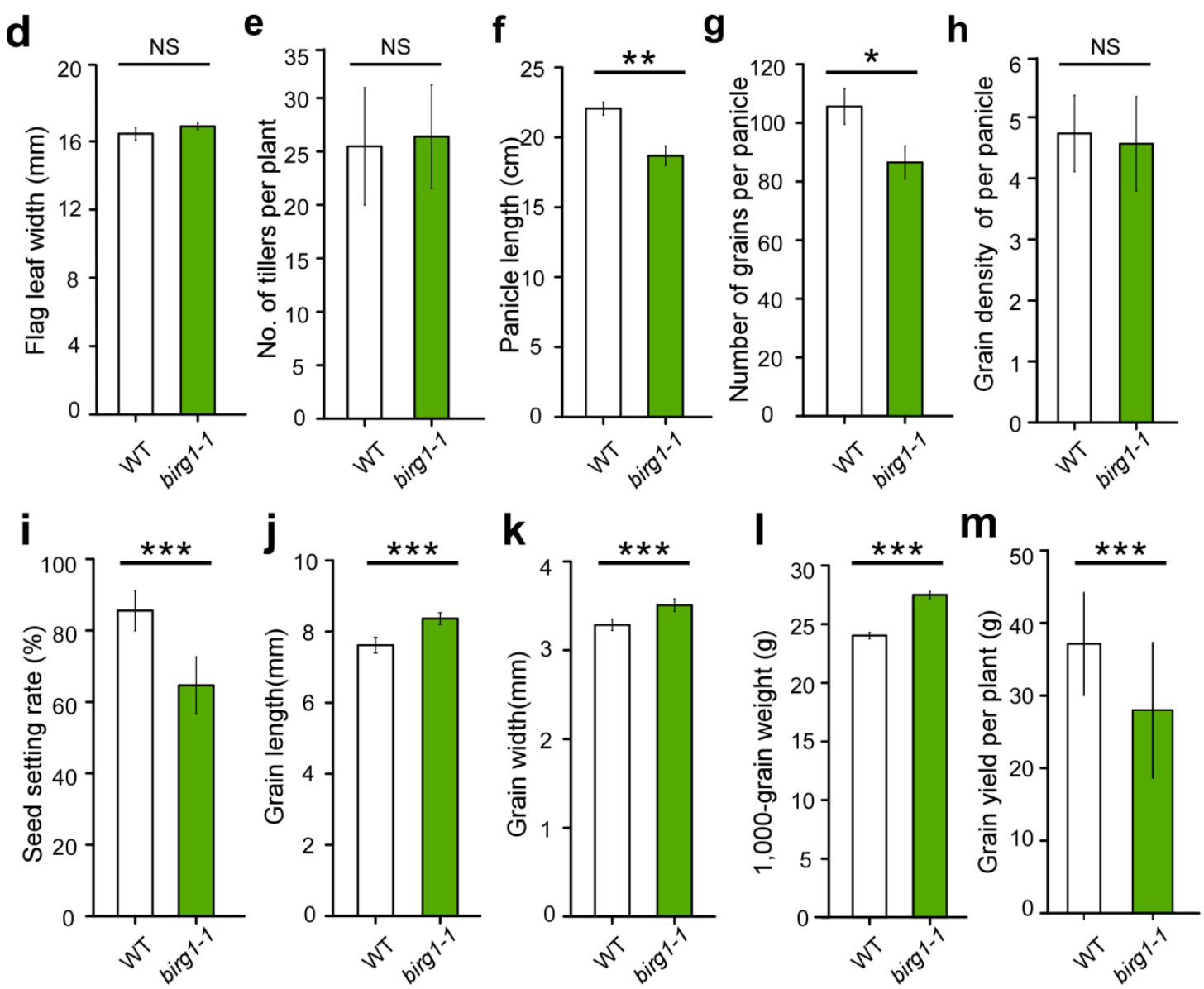

Fig. S4. Agronomic traits of the WT and birgl. (a) Plant height of the WT and birgl as in (A), n=20. (b) Flag leaf length from different plants, n=20. (c) Flag leaf width (Measure the widest area), $n=20$. (d) Internode length, $n=20$. (e) Tiller number (Effective tiller number), $\mathrm{n}=20$. (f) Panicle length, $\mathrm{n}=20$. (g) Number of grains per panicle, $n=20$. (h) Grain density of per panicle, $n=20$. (i) Seed setting rate, $n=20$. (j) Grain length, n=20. (k) Grain width, n=20. (1) 1,000-grain weight, n=3. (m) Grain 
yield per plant, $\mathrm{n}=30$. Data shown as means $\pm \mathrm{SD}, p$ Value based on Student's $t$-test, * $p<0.05$, ** $p<0.01$ and $* * * p<0.001$.

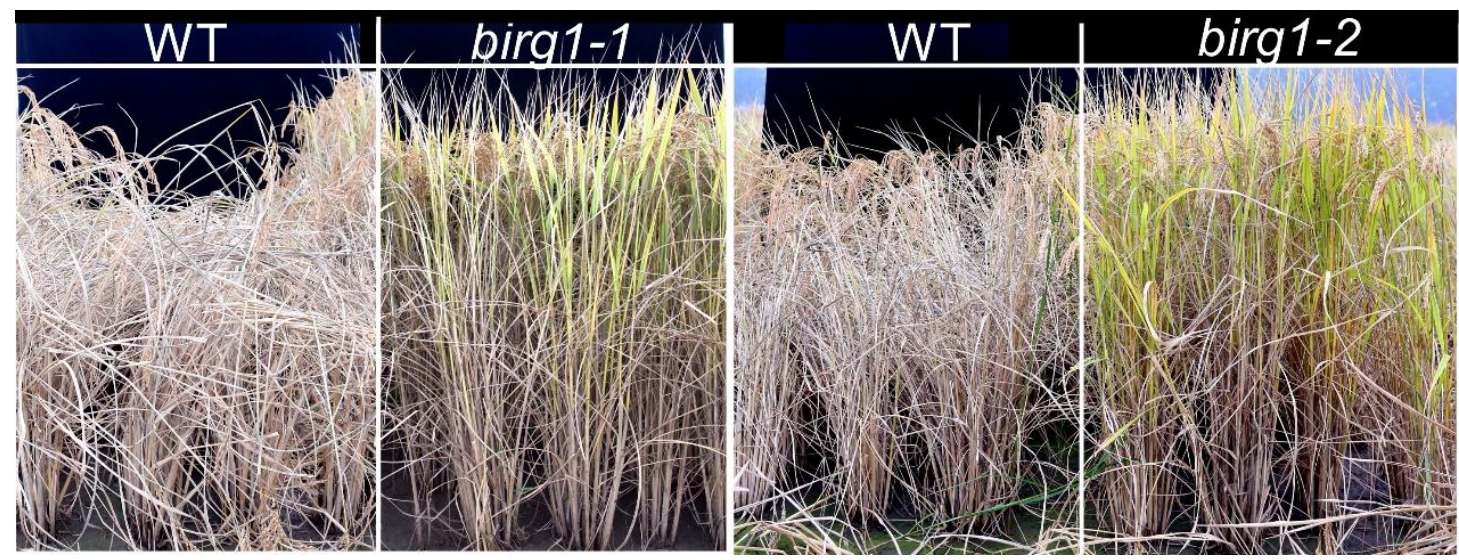

Fig. S5 The birgl mutants exhibit improved lodging resistance. WT and birgl at the mature stage were shown.

a

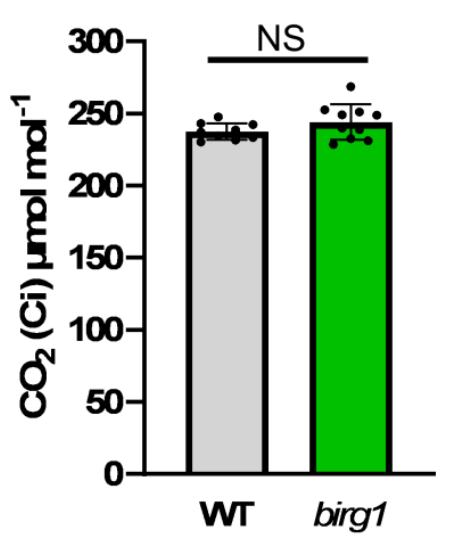

C

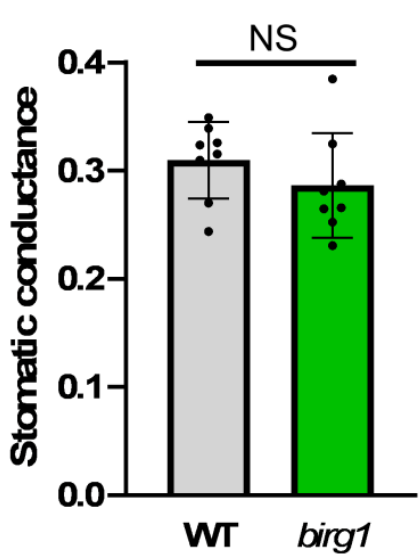

b

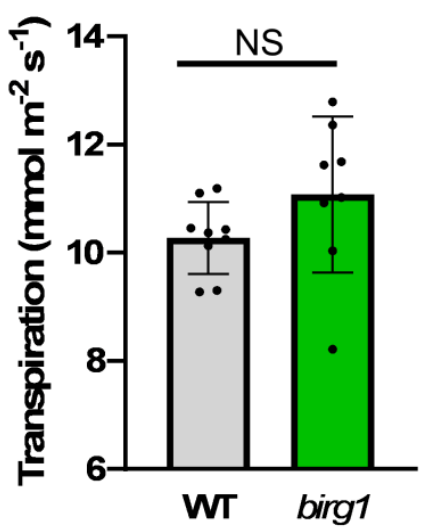

d

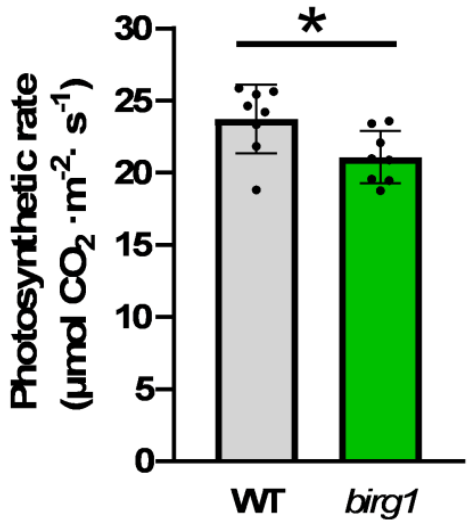


Fig. S6 The photosynthetic capacity of WT and birgl. (a) Intercellular $\mathrm{CO}_{2}$ concentration. (b) Transpiration efficiency. (c) Stomatic conductance. (d) photosynthetic rate. Means $\pm \mathrm{SD}$ are given $(\mathrm{n}>=8), p$ value (Student's $t$-test, two-tailed), $* p<0.05$.

a

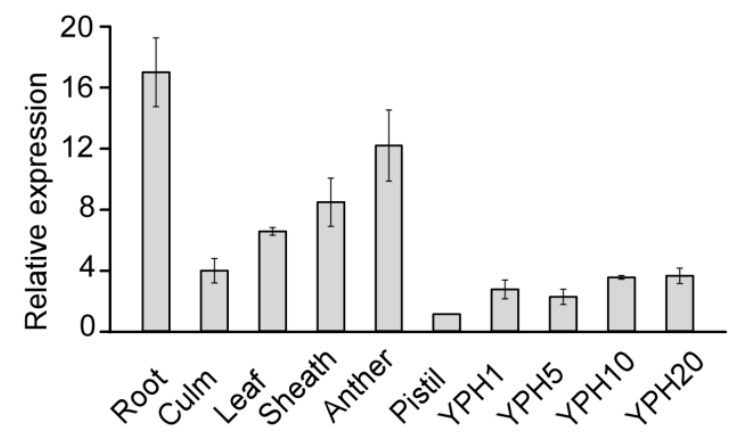

b ロ WT ロ birg1-1

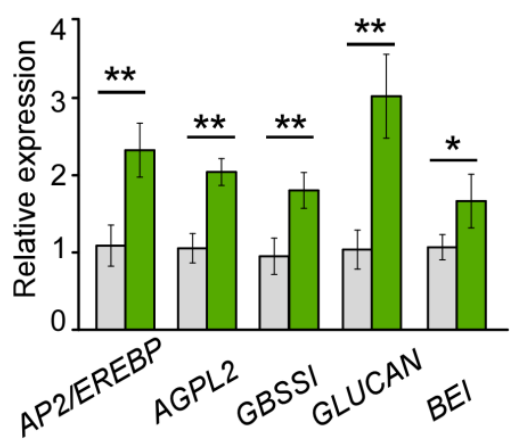

d $\square$ WT-DAF5 $\square$ birg1-1-DAF5

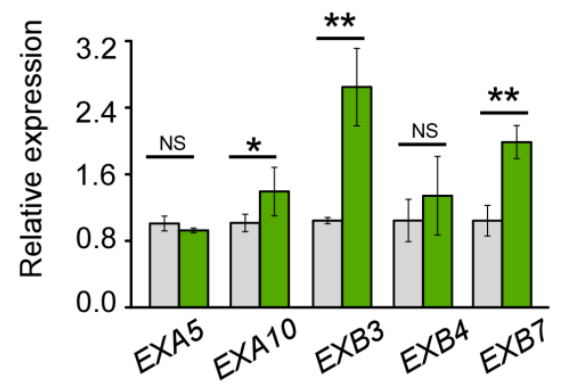

Fig. S7 Expression of BIRG1 in various organs and expression of genes involved in starch synthesis, cell cycle and cell expansion related genes in the WT and birg1 analyzed by QRT-PCR. (a) Root, culm, leaf, and sheath were harvested from before heading WT plants. Anther and pistil were collected from spikelet hulls two days before fertilization. Young panicles heading (YPH) in different lengths (indicated as numbers, cm) were included for the analysis. (b) QRT-PCR analysis showed that expression levels of starch synthesis-related genes in birgl mutant were elevated compared with that in WT. Starch synthesis-related genes and ID: RSR1/AP2/EREBP (Os05g0121600), AGPL2 (Os01g0633100), GBSSI (Os06g0133000), GLUCAN (Os01g0533100), BEI (Os06g0726400). (c)Transcription levels of cell cycle (G1 to S phase)-related genes in 5 DAF seeds of birgl relative to that of the WT. Cell 
cycle-related genes: CDKA1 (Os03g0118400), CYCD1;1 (Os06g0236600), CYCT1 (Os02g0133000), H1 (Os03g0737600) and E2F2 (Os12g0158800). (d) Transcription levels of cell expansion-related genes in 5 DAF seeds of birgl relative to that of the WT. Cell expansion-related genes: EXA5 (Os02g0744200), EXA10 (Os04g0583500), EXB3 (Os10g0555900), EXPB4 (Os10g0556100) and EXB7 (Os03g0102700). The rice ACTIN1 gene was used as an internal control. Error bars shown as mens $\pm \mathrm{SD}$, and Student's $t$-test identify significant differences at the $p<0.05, * p<0.05$, ** $p<0.01$ and $* * * p<0.001$. 

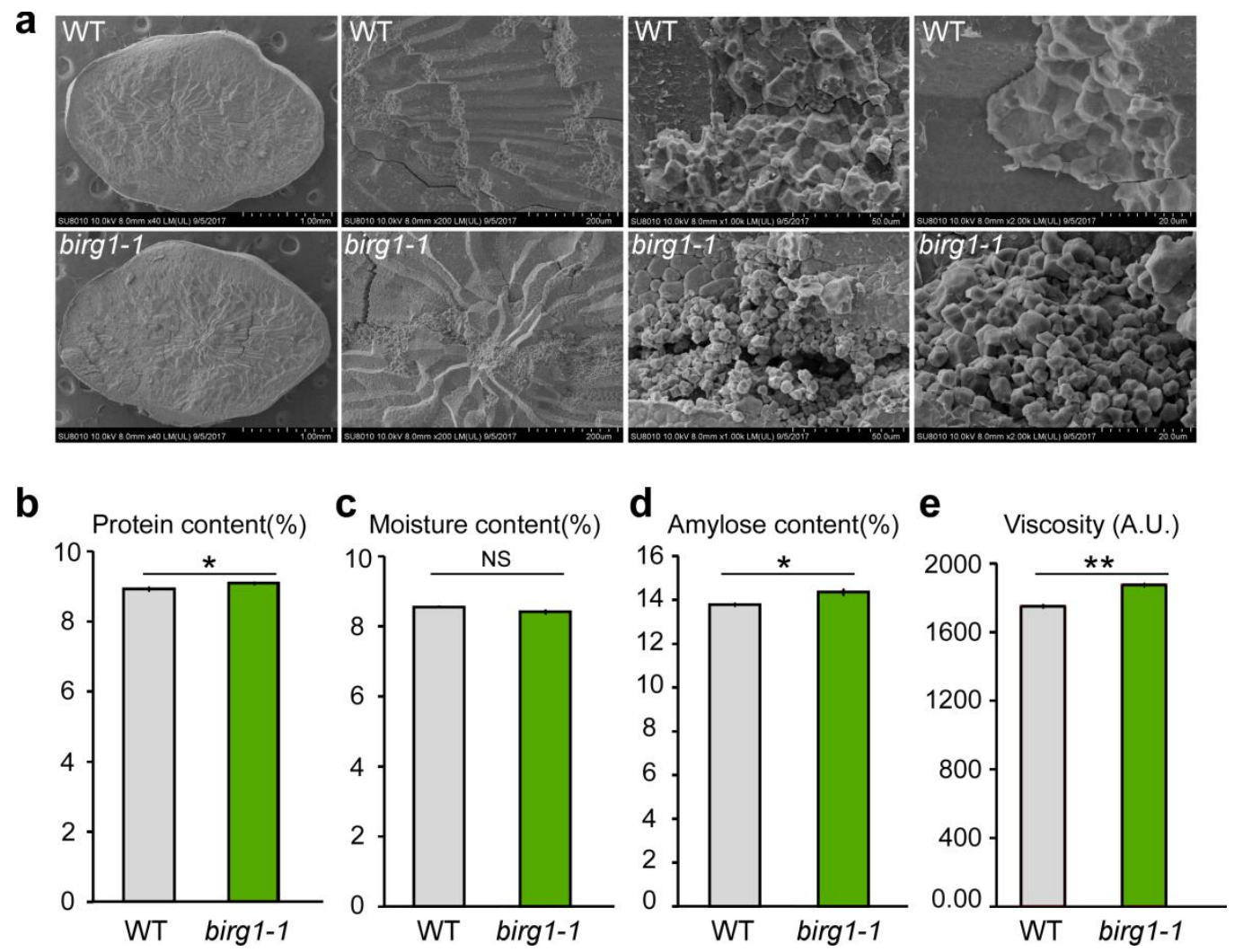

Fig. S8 Scanning electron microscopy (SEM) analysis of WT and birgl mutant endosperm and physicochemical properties of starch in birgl grain. (a) The birgl mutant showed smaller and loosely packed starch grains as compared to large and tightly packed ones in the WT. Scale bars: $1 \mathrm{~mm}$ (the left row), $200 \mu \mathrm{m}$ (second row), $50 \mu \mathrm{m}$ (third row), $20 \mu \mathrm{m}$ (right row). (b-d) Protein (b), moisture (c) and amylose (d) contents in mature caryopses of the WT and birgl mutant. (e) The viscosity of birgl pasting starch was higher than that of the WT. Data shown as mens \pm SD $(n=3 ; * p$ $<0.05, * * p<0.01$, Student's $t$-test). 
Table S1. DTX/MATE family genes highly expressed in spikes

\begin{tabular}{|c|c|c|}
\hline Candidate genes & Gene NO. & TRAP-Seq FPKM Expression \\
\hline OsDTX1 & LOC_OsO6g29950 & Seeding, Seed (S5 Stage) \\
\hline OsDTX2 & LOC_Os01g49120 & Seeding, leaf, Seed (S4 and S5 Stage) \\
\hline OsDTX3 & LOC_Os02g57570 & Seed (S3 and S4 Stage) \\
\hline OsDTX4 & LOC_Os03g64150 & Root, Seed (S3 and S4 Stage) \\
\hline OsDTX5 & LOC_OsO8g43250 & Panicles, Seed（S4 Stage） \\
\hline OsDTX6 & LOC_Os03g12790 & Seed ( S4 and S5Stage) \\
\hline OsDTX7 & LOC_Os03g62270 & Root, Seeding \\
\hline OsDTX8 & LOC_Os08g44870 & Seeding, leaf \\
\hline OsDTX9 & LOC_Os11g03484 & Seed (S4 and S5 Stage) \\
\hline OsDTX10 & LOC_Os08g43654 & Root, Seeding, Panicles \\
\hline
\end{tabular}


Table S2. Primers used in this study

Primer Name

Primers for QRT-PCR

BIRG1-RT-F

BIRG1-RT-R

ACTIN1-RT-F

ACTIN1-RT-R

CDKA1-RT-F

CDKA1-RT-R

CYCD1;1-RT-F

CYCD1;1-RT-R

CYCT1-RT-F

CYCT1-RT-R

H1-RT-F

H1-RT-R

E2F2-RT-F

E2F2-RT-R

OsEXPA5-RT-F

OsEXPA5-RT-R

OsEXPA10-RT-F

OsEXPA10-RT-R

OsEXPB3-RT-F
Primer sequence

TAGTTTCTGCATCCCGTTTGGG

GTTGCAGTTGTTGTTCATGCAAGC

TGGCATCTCTCAGCACATTCC

TGCACAATGGATGGGTCAGA

GGTTTGGACCTTCTCTCTAAAATGC

AGAGCCTGTCTAGCTGTGATCCTT

CCGTCGCTCGCATTCGTA

TCATGTGCCTGGTGGTGA

GCTTCTTTCAGAGGGTCAT

GCATTTCAAGTACACGAGGT

GCAAGGCACCTGCAGCTT

AGGCAGCCTTTGTACAGATCCT

TGTTGGTGGCTGCCGATAT

CGCCAGGTGCACCCTTT

AAGGCTGTGGCTTGATTGACA

TTAGGCCCAATTTTGCTATTTTG

TGACCAACTACAACGTGGTCCC

GCCAGTGTATGTTTTGCCGAAG

CTTTGAGTGGTTGGAGTGGTGG 
OsEXPB3-RT-R

OsEXPB4-RT-F

OSEXPB4-RT-R

OsEXPB7-RT-F

OsEXPB7-RT-R

AP2/EREBP-RT-F

AP2/EREBP-RT-R

$B E I-\mathrm{RT}-\mathrm{F}$

BEI-RT-R

GBSSI-RT-F

GBSSI-RT-R

GlUCAN-RT-F

GIUCAN-RT-R

AGPL2-RT-F

AGPL2-RT-R

Primers for construct $p B I R G 1: G U S$

pBIRG1-F

pBIRGI-R

Primers for subcellular localization

BIRG1-GFP-F

BIRGI-GFP-R

Primers for transgenic constructs
GCAGCCTTCTTGGAGATGGAA

GTCGGTCTGTGTTGCGATTTG

CCTCCATTTCCCACACAGCTT

ACGGTGATCATCACGGACAT

TCGAAGTGGTACAGCGACACT

CGCCATTGTTCAGCAAGGAGA

GCACAACACAACCACAAAAGTGC

ATTTTATGGGCAATGAGTTTGGC

AGGCTCCACTGACGTCTGCAT

GCATCACCGGCATCGTCAAC

GCCTCGATTGCCGTGGTTG

CCGCGATCAGAAACTATGGACA

TCCCAGATGTCCTTGGCGTACT

GCATAGATAGGCCTTGGAATCGC

CATGGAGGCTACGCTATCCGTCT

TGAGTAGTTATTGTCAGCTCTCGCTAGG

GGCCGGGTGG CAAACTCGAT AGAT

ATGACGCCTCCACCGCCGTCGC

AGGCTGGACGACCTCGTCGTG 
BIRG1-CRISPR-F

BIRG1-CRISPR-R

BIRG1-TALENs-region

BIRG1-Ri-F

BIRG1-Ri-R

Primers for expression construct

BIRG1-pGEMHE-F

BIRG1-pGEMHE-R
CCGCCATGGACCCCATCTGCGGG

CCCGCAGATGGGGTCCATGGCGG

CGCCGTCCTCACCGGCCTCTGCGCCGCCA

TGGACCCCATCTGCGGGCAGGCGC

TGCGCCGCCATGGACCCCATC

GGCGGAGGCGAACAGCGTGGG

ATGACGCCTCCACCGCCGTCGC

TCAAGGCTGG ACGACCTCGT CGTG 